Nanomaterials for Magnetic and Optical Hyperthermia Applications

Chapter 6

\title{
Nanoscale Thermometry for Hyperthermia Applications
}

Rafael Piñol*, Carlos D.S. Brites ${ }^{\dagger}$, Nuno J. Silva ${ }^{\dagger}$, Luis D. Carlos ${ }^{\dagger}$ and Angel Millán*,1

†CICECO-Aveiro Institute of Materials, University of Aveiro, Aveiro, Portugal *ICMA-Instituto de Ciencia de Materiales de Aragón, CSIC-University of Zaragoza, Zaragoza, Spain

${ }^{1}$ Corresponding author: e-mail: amillan@unizar.es 


\begin{abstract}
The importance of high-resolution intracellular thermal sensing and imaging in the field of modern biomedicine has boosted the development of novel nanosized fluorescent systems (fluorescent nanothermometers) as the next generation of probes for intracellular thermal sensing and imaging. This thermal mapping requires fluorescent nanothermometers with good biocompatibility and high thermal sensitivity in order to obtain submicrometric and subdegree spatial and thermal resolutions, respectively. This chapter revises the different nanometric systems that have been proposed to date for intracellular thermal sensing and imaging. We also include the later advances in molecular systems based on fluorescent proteins for thermal mapping. A critical overview of the state of the art and the future perspective is also included.
\end{abstract}

Keywords: Optical hyperthermia, Magnetic hyperthermia, Intracellular heating, nanothermometry, luminescent thermometry.

\title{
6.1 Introduction
}

Hyperthermia therapy based on the use of nanoparticles has been an important issue in Nanobiomedicine since the beginning of this discipline [1]. The basic idea is to use nanoheaters that are selectively accumulated in the diseased tissue and then non-contact heated by an external power source. At a first sight, the potential of this approach is enormous because the small size and the use of appropriate coatings and targeting agents would allow the application of heat locally to specific cell organelles in selected cell types, in a non-invasive manner. Therefore, although the slow progress in the field is sometimes frustrating, the expected reward is worth the effort. One of the major issues to achieve non-secondary effects and enhanced effectiveness is reaching the targeted diseased cells [2]. But this goal has met a bottleneck: most types of nanoheaters are retained in non-targeted organs [3] such as liver and spleen by the reticuloendothelial system (RES), or even worst, in the lungs where they may cause serious toxicity problems. So one of the main challenges in the field is to avoid the RES. Other problems are intrinsic to the heating technique. Thus, in magnetic hyperthermia the achievable heating power is small and that leads to the need of a large amount of nanoparticles to destroy malignant tissues by a global temperature increment. In optical hyperthermia, that yields a high specific heating power, the restrictions come from a poor light penetration in tissues. Thus, although magnetic hyperthermia has already been used for the treatment of some types of cancer [4], these techniques are still far from being a competitive alternative to surgery. Actually, current magnetic hyperthermia involves the patient intervention with thermometric probes to control the heating and needles to inject the magnetic nanoparticles, and therefore it is not completely non-invasive [4]. Moreover, it causes problems derived from nanoparticle and cell detritus evacuation after the treatment. It is evident that this approach is not taking advantage of the capacity of nanoparticles to penetrate cell membranes, and to produce heat at specific temperature sensitive organelles inside the cells.

The concept of local intracellular hyperthermia is to produce local damage in small regions within the cells that could trigger an apoptosis reaction in these cells (see Chapter 8 for an overview of mechanisms of cellular death induced by hyperthermia). At the present moment, this has not fairly proven, but there are evidences that cells can be killed by magnetic hyperthermia without raising the global cell temperature [5]. In order to evaluate the possibilities of this approach the first step is to check whether the heat generated by a nanoheater is high enough to overcome the heat conduction effect 
through the cell medium in order to produce a high enough temperature gradient in the surroundings. For this task, an extra tool becomes necessary, a thermometer capable of measuring the local temperature in the nanoheathers. The scope of this chapter is precisely to explore the actual technologies available for temperature determination in the nanoscale, and their applicability to intracellular hyperthermia.

\subsection{High spatial resolution thermometry}

The design of nanothermometers addresses spatial resolution as the main goal, while keeping temporal and temperature resolution at convenient levels. These levels can be even more severe than those of macroscopic thermometry, since the temperature gradients of interest in nanothermometry are often of the order or smaller than $1^{\circ} \mathrm{C}$ and the duration of the gradients (induced by hyperthermia or by chemical reactions, for instance) can be of the order or smaller than $1 \mathrm{sec}$. In most cases, spatial, temporal and temperature resolutions are entangled: the increase of spatial and temperature resolution is often made at the expenses of time resolution (by using larger integration times of the thermometric signals) and the increase of temporal and temperature resolution is often made at the expenses of spatial resolution (by using larger integration areas).

When considered alone, spatial resolution in nanothermometry is the result of a convolution between three main sources of limitations: the contribution due to the size of the material, the contribution due to the instrumentation reading this response and the limitations of the fundamental principles involved. The wide range of present spatial resolutions and ultimate resolutions that are expected to be achieved is then due to the wide range of materials, methods and principles.

Thermometers where resolutions are greatly constrained by fundamental principles include infrared thermography, optical interferometry and thermoreflectance, where typical spatial resolutions are 10,1 and $0.1 \mathrm{~mm}$, respectively, and constrains in spatial resolution are associated with the "size" of the wavelengths. Near-field methods, opened a possible increase of spatial resolutions of optical methods down to $\sim 10 \mathrm{~nm}$ [6]; however this has not been widely explored in thermometry with high spatial resolution. Another way to overcome the wavelength constrain in thermometry techniques based on light is the use of local sources of light. In such techniques, although the signal output is light in the visible or near visible range with the associated wavelength limitation, the signal emerges from well defined "spots" with smaller sizes (luminescent nanoparticles, quantum dots and dyes, for instance) and thus temperature can be associated to those spots.

The spatial resolution of nanothermometers based on luminescent nanoparticles or molecules is no longer constrained by fundamental limitations but by the instrumentation reading the optical response. In this family of nanothermometers, spatial resolution is presently on the order of $1 \mathrm{~mm}$ (constrained by optical imaging) see, for instance [7-9], while the ultimate resolution can in principle be associated with the size of the luminescent molecule or nanoparticle. This is also the case of nanothermometers based in nanodiamonds, where spatial resolution is presently on the order of $1 \mathrm{~mm}$ (constrained by confocal imaging) [10], while the ultimate resolution is the size of one nanodiamond $(\sim 5 \mathrm{~nm})$.

A family of nanothermometers where spatial resolution is constrained by the instrumentation and by the size of the material is that of scanning based systems. In this case, resolution is of the order of the probes or tips, between 1 and $0.02 \mathrm{~mm}$. Such systems include (micro)Raman, fluorescence with detection by optical fibers [11] and fluorescence coupled to atomic force microscopy (AFM) tips [12]. As expected, this family of nanothermometers is probably closer to their ultimate resolution. 
Nanothermometers constrained by the size of the materials are typically those based on the miniaturization of concepts and principles often used at the macroscopic scale. This includes micro-sized thermocouples and nanovessels. The thermocouples explore the thermoelectric effect in the limits of production of a two-metals junction. The nanovessels explore the liquid expansion inside a container, such as nanotubes filled with a liquid metal, being the size as small as a few nanometers. In this case the detection method is the observation by electron microscopy, which does not constrain the spatial resolution but clearly limits their practical use.

In the following we will concentrate on luminescent thermometry as the method gathering the best conditions for non-contact high-resolution thermometry and best perspectives in terms of ultimate resolutions. We will also give more details on the quantification of spatial resolution in section 6.3.4. ("Quantifying the thermometer's performance").

\subsection{Luminescence thermometry}

The main approaches to determine the temperature through luminescence thermometry can be gathered as time-integrated or time-resolved methodologies (Figure 6.1). In the first, the emitted intensity is integrated during a certain time interval and the temperature is calculated from the intensity of one transition or from the intensity ratio of two transitions. On the other hand, in time-resolved methodologies after an initial excitation the emitting excited state decay curve is followed with respect to the time. In time-integrated methods the spectral shift, width or simply the integrated intensity of a given transition is analyzed with respect to the temperature, or, alternatively, the integrated intensity of a pair of transitions, can be used to define a ratio of intensities.

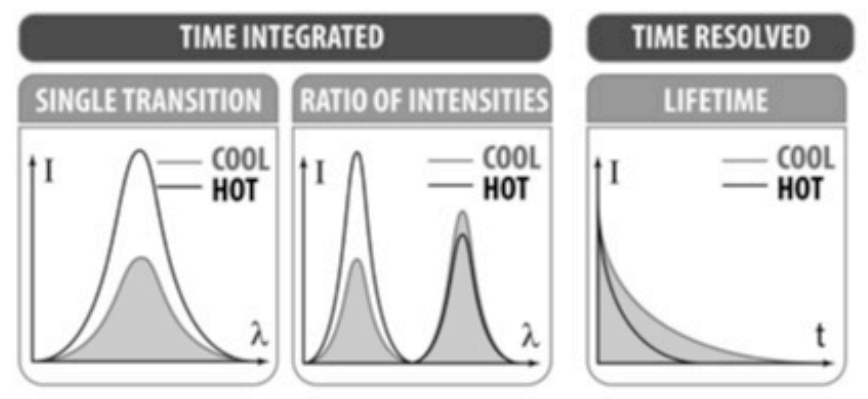

Figure 6.1. Time integrated and time resolved methods to infer the temperature using the luminescence of a phosphor. 
Luminescent thermometers based on the emission intensity of a single transition depend critically on the illumination fluctuations and the local changes of the phosphor concentration. Proof-of-concept luminescent thermometers were reported using a single transition of $\mathrm{Ln}^{3+}$ ions [13,14] quantum dots [15-18] and organic molecules [19-24]. Although the methodology is not incorrect recursive calibration procedures are required, thus becoming impractical. The limitations of a single transition integration can, however, be mitigated using a second emission line (or band) that is an internal standard to calibrate the response of the luminescent probe $[25,26]$. Works reporting $\mathrm{ZnCdS}$ quantum dots (QDs) [27] and $\mathrm{CdS}: \mathrm{Eu}^{3+}$ phosphors [28] motivate the development of luminescent probes based on a pair of transitions of two distinct emitting centers or from a single emitting center, as reviewed in several papers [29-31], books [32], and book chapters [33]. With the increasing interest in nanoparticles, particularly using upconverting emission, a popular approach infers the absolute temperature from the intensities of two energy levels (or two Stark components of an excited state) in thermal equilibrium

The temperature scale is based exclusively upon the validity of the Boltzmann distribution between the adjacent energetic levels:

$$
\Delta=\frac{I_{1}}{I_{2}}=B \exp \left(-\frac{\Delta E}{k_{B} T}\right)
$$

where $k_{\mathrm{B}}$ is the Boltzmann constant and $B$ is a pre-exponential constant depending on the spontaneous emission coefficients, energy and degenerescencies of levels $\mid 1>$ and $\mid 2>, \Delta E$ is the energetic separation between the excited levels $\mid 1>$ and $|2\rangle$ in thermal equilibrium and $T$ is the absolute temperature (Figure 6.2A). It is based on the thermally driven redistribution of the excited levels (notice that $k_{\mathrm{B}} T \sim 200 \mathrm{~cm}^{-1}$ at room temperature). To validate the use of Eq. 6.1 it is common to fit the dependence of $\ln (\Delta)$ with the inverse of the temperature and compare the fitted slope with the value expected for $\Delta E / k_{\mathrm{B}}$ (Figure 6.2B). If, within the experimental errors, both values are consistent, the emitting levels are assumed to be in thermal equilibrium, following the Boltzmann law. This is a non-empirical procedure that interrogates the intensity ration of intensities from two excited levels that are energetically close (the energy gap between 200 and $2000 \mathrm{~cm}^{-1}$ ), allowing to estimate the temperature overcoming the need of tedious and time-consuming calibration procedures. 


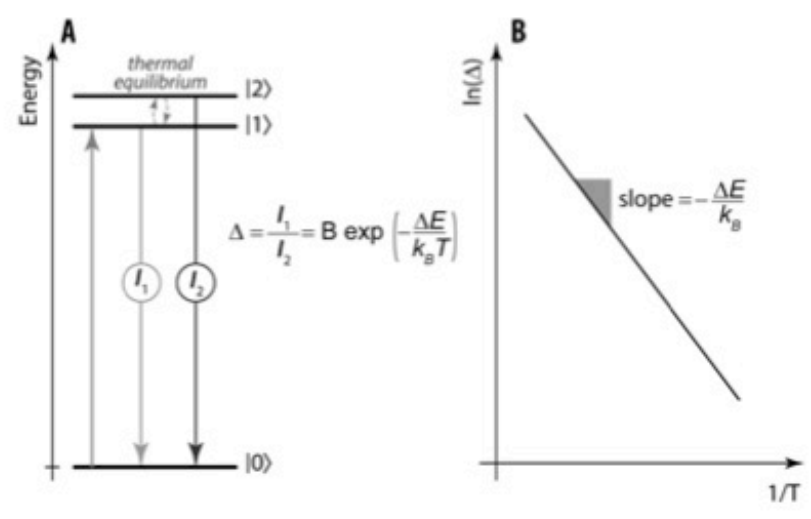

Figure 6.2. (A) Scheme of the typical energy diagram of an emitting center with two thermally-coupled levels. (B) The plot of $\ln (\Delta)$ against $1 / T$ validates the use of Boltzmann law.

Lifetime-based sensing methods do not suffer from the above-mentioned disadvantages of the single-transition intensity technique. However, comparing with the ratiometric intensity response to temperature changes, they require longer acquisition times, postprocessing techniques and the complexity and demands on the component instrumentation increase with the decreasing decay times [29,34,35]. Moreover, lifetime-based sensing methods are less appropriate for large-area gradient temperature measurements and very inappropriate to study dynamic measurements in which temperature variations occur at time intervals shorter than or equal to the lifetime of the probe (e.g., $10^{-3} \mathrm{~s}$ for $\mathrm{Ln}^{3+}$ ions).

\subsubsection{Advantages and challenges of luminescent nanoprobes}

Liquid-filled and bimetallic thermometers, thermocouples, pyrometers, and thermistors, are classified as contact thermometers and are generally not appropriate for temperature determination at scales below $10 \mu \mathrm{m}$ [29,31-36]. As the contact measurements require conductive heat transfer from the object to the probe, the thermal equilibrium between them is needed to provide a reliable estimative of the object's temperature. This thermal connection disturbs the temperature of the sample during the measurement, especially for systems with a small size when compared to that of the probe's sensor head [31].

The limitations of contact thermometers to disclose thermal processes, especially in small systems where submicron spatial resolution is desirable scale have spurred the development of new non-contact (semi-invasive and noninvasive, Figure 6.3) accurate thermometers using the changes in the light emitted or absorbed by a thermal probe. It is now well spread in the literature that the temperature measurements based on 
intensity changes require ratiometric readout. The intensity ratio between two transitions is not compromised by the well-known disadvantages of experiments based on the intensity of only one transition, such as the critical dependence on variations of the sensor concentration, eventual material inhomogeneities and optoelectronic drifts of the excitation source and detectors [30,31,37].

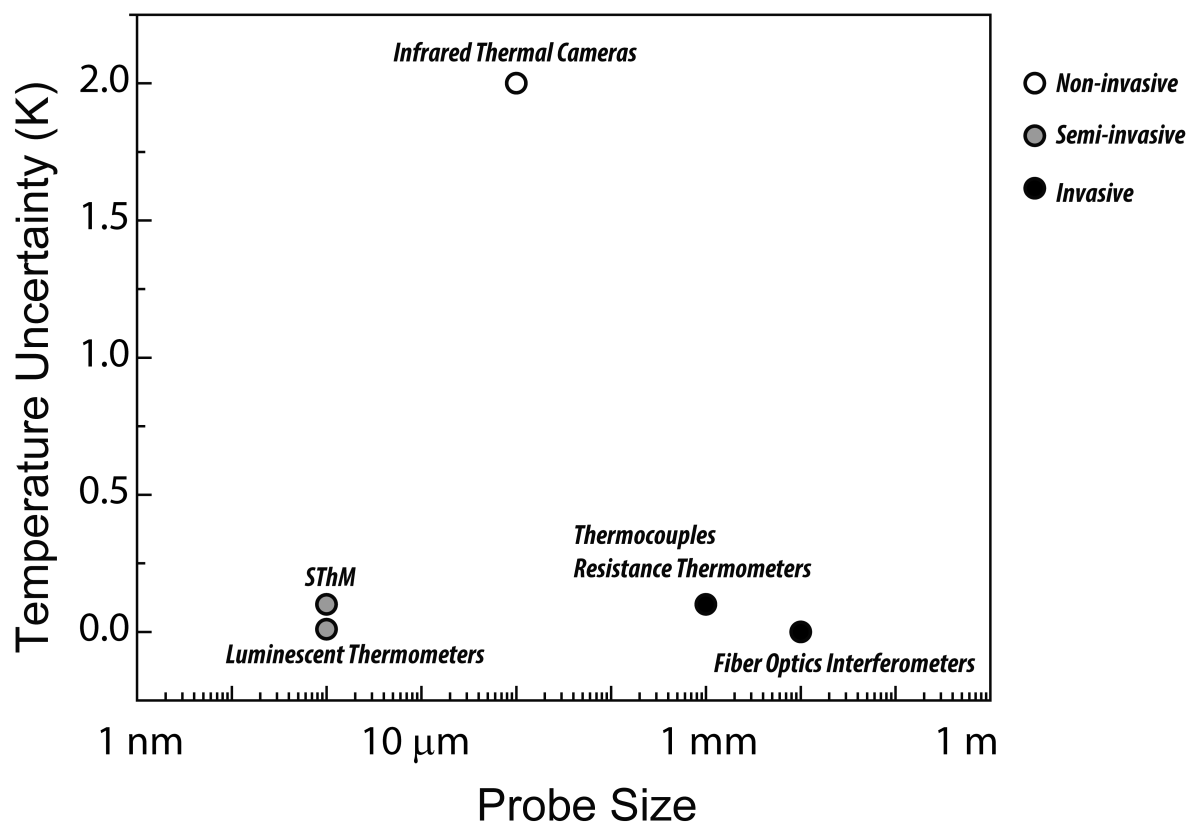

Figure 6.3. Comparing the typical temperature uncertainty and probe size of distinct methods to measure the temperature.

From the materials point-of-view, luminescent thermal probes are derived from organic dyes, ruthenium complexes, spin crossover nanoparticles, polymers, layered double hydroxides (LDHs), QDs and $\mathrm{Ln}^{3+}$-based materials. Molecular thermometers based on light-absorbing aromatic compounds [29], Rh101 [39], RhB [40], Rh 101/Rh B [41], fluorescein isothiocyanates [42], and cyanine dyes [8] are used for temperature determination, essentially in biological context [22]. QDs have been proposed for submicron thermometry, since they present temperature dependent luminescence (intensity changes or emission peak shifts) $[15,43]$ and are well suited to operate in the spectral region of low absorption of the biological tissues. Nanomedicine stands out as the most appealing area, since bioconjugation of QDs can make them target selective. Although QDs are often composed of highly cytotoxic elements (e.g. Cd) which makes difficult their future use in clinical trials [44,45], many intriguing results are being reported using QDs for in vivo biologic deep imaging in laboratory mouse models.

Despite the promising features of luminescent thermometers, the market of non-contact temperature sensors is clearly dominated by the infrared pyrometry that is used in pyrometers and infrared thermal cameras. The relatively low accuracy of this technique, typically 2-5 K, combined with the difficulty to set the correct emissivity of an unknown surface is balanced with the fully non-contact nature of the technique. On the other hand, in luminescent thermometry a minimally invasive molecular probe needs to be in contact with the object, and as a revenue, the thermal uncertainty can be dropped by one order of magnitude, to $0.2-0.5 \mathrm{~K}$, using portable spectrometers. Moreover, 
contrary to the infrared pyrometry or contact thermometers, the luminescent probes present the critical advantage of can be designed to be excited inside of the biological tissues, permitting to recover the emitted signal (and thus the temperature) from the outside of the biological tissue.

\subsubsection{The peculiar example of trivalent lanthanide ions $\left(\mathrm{Ln}^{3+}\right)$}

The uniqueness of $\mathrm{Ln}^{3+}$ ions (the most prevalent oxidation state in which lanthanide elements are present in nature) lies on their electronic configuration corresponding to $4 \mathrm{f}^{\mathrm{N}}$ (where $\mathrm{N}=1-14$ ). The shielding of the $4 \mathrm{f}$ electrons from interactions with their surroundings (ligand-field interaction) by the filled $5 \mathrm{~s}$ and $5 \mathrm{p}$ orbitals is responsible for the interesting chemical and photophysical properties of the $\mathrm{Ln}^{3+}$ ions $[46,47] . \mathrm{Ln}^{3+}$ based materials are versatile, stable and narrow band emitters, presenting typically emission quantum yields values higher than 50\% [48-51]. As different $\mathrm{Ln}^{3+}$ centers cover the electromagnetic spectrum from the UV (e.g. $\mathrm{Gd}^{3+}$ ) to the IR (e.g. $\mathrm{Er}^{3+}, \mathrm{Yb}^{3+}$, $\mathrm{Nd}^{3+}$ ), it is virtually possible to design luminescent probes for a large variety of applications [47,49-54], namely for $\mathrm{pH}$ [55], oxygen [56] and temperature sensing. Numerous $\mathrm{Ln}^{3+}$-based molecular thermometers have been reported, covering temperature ranges including the cryogenic $(T<100 \mathrm{~K})$, physiological $(298-323 \mathrm{~K})$ and high-temperature $(400<\mathrm{T}<1500 \mathrm{~K})$ intervals. The probes involve chelate complexes [13,36,37], metal-organic frameworks [57-59], upconverting NPs (UCNPs) [60-62], or downshifting nanomaterials [63-65].

Wang et al. were the first authors suggesting the use of the changes on the luminescent properties of nanoparticles for thermometry [66]. Using $\mathrm{ZnS}: \mathrm{Mn}^{2+}, \mathrm{Eu}^{3+}$ nanoparticles, the ratio of the emission intensities of the two dopants was used for temperature determination, the so-called fluorescence intensity ratio, FIR. A few years later, this same FIR concept was generalized to NPs doped only with $\mathrm{Ln}^{3+}$ ions, $\mathrm{BaTiO}_{3}: \mathrm{Er}^{3+}$ UCNPs [67]. In $\mathrm{Er}^{3+}$-based systems, the FIR method involves measurements of the fluorescence intensities from two closely spaced electronic energy levels $\left({ }^{2} \mathrm{H}_{11 / 2}\right.$ and ${ }^{4} \mathrm{~S}_{3 / 2}$ ) that are thermally coupled (e.g., in a thermodynamically quasi equilibrium state) $[68,69]$. Later, the development of siloxane-based hybrid magnetic nanoclusters doped with $\mathrm{Eu}^{3+}$ and $\mathrm{Tb}^{3+}$ chelates opened the possibility of using emission from two emitting centers [37]. In this example, the rational design of the hybrid host to have an excited state with energy slightly above that of the $\mathrm{Tb}^{3+}{ }^{5} \mathrm{D}_{4}$ emitting state, guarantees the occurrence of thermally-driven ${ }^{5} \mathrm{D}_{4} \rightarrow$ host energy transfer and, consequently, the determination of the temperature dependence of the ${ }^{5} \mathrm{D}_{4}$ emission. As the energy difference between that triplet state and the $\mathrm{Eu}^{3+5} \mathrm{D}_{0}$ emitting level is too large to permit its thermally driven depopulation, the ${ }^{5} \mathrm{D}_{4} \rightarrow{ }^{7} \mathrm{~F}_{5} /{ }^{5} \mathrm{D}_{0} \rightarrow{ }^{7} \mathrm{~F}_{2}$ relative intensity ratio guarantees the absolute measurement of temperature. Similar energy resonance schemes may be obtained using other hybrid or polymer hosts or $\beta$-diketone chelates with different ligands [70,71]. This mechanism involving the host excited state is different than that usually observed in $\mathrm{Tb}^{3+} / \mathrm{Eu}^{3+}$-doped materials in which the temperature dependence of the ${ }^{5} \mathrm{D}_{4} \rightarrow{ }^{7} \mathrm{~F}_{5} / \mathrm{D}_{0} \rightarrow{ }^{7} \mathrm{~F}_{2}$ intensity ratio is determined by the $\mathrm{Tb}^{3+}$-to-Eu $\mathrm{Eu}^{3+}$ energy transfer [72], that occurs essentially through the dipole-quadrupole and quadrupole-quadrupole mechanisms [73]. The use of $\mathrm{Tb}^{3+}$-to-Eu ${ }^{3+}$ energy transfer as a tool to temperature sensing was firstly proposed by Sato et al. in 1989 [74] and revisited by Liu et al. in 2005 [75].

\subsubsection{Downshifting versus upconversion in $\mathrm{Ln}^{3+}$ : benefits and challenges}

In the time-integrated methodology there are two main physical mechanisms that can generate the luminescent signal after a photon of a certain energy being absorbed. When 
the energy of the absorbed photon is higher than that of the emitted one, generally the process involves non-radiative deactivation processes and as outcome a lower energy photon (higher wavelength) is emitted. This linear process, called Stokes emission or downshifting, is operative even for low power values. Typical $\mathrm{Ln}^{3+}$ downshifting probes (e.g. $\mathrm{Eu}^{3+}, \mathrm{Tb}^{3+}, \mathrm{Tm}^{3+}, \mathrm{Sm}^{3+}$ ) absorb ultraviolet radiation and emits in the visible spectral range. On the other hand, the absorption of several photons of lower energy to generate a single photon of higher energy is a non-linear process (called anti-Stokes emission or upconversion) that is also possible to be used for temperature probing. The most studied $\mathrm{Ln}^{3+}$ ion for luminescence thermometry by upconversion is the $\mathrm{Er}^{3+}$ that combines the ${ }^{4} \mathrm{I}_{11 / 2}$ level almost resonant with the ${ }^{2} \mathrm{~F}_{5 / 2}$ level of $\mathrm{Yb}^{3+}$ and two closely energy levels $\left({ }^{2} \mathrm{H}_{11 / 2}\right.$ and $\left.{ }^{4} \mathrm{~S}_{3 / 2}\right)$ that are used to infer the temperature through the Boltzmann law. The $\mathrm{Yb}^{3+}$ ion takes the role of sensitizer due to the high absorption cross section at $980 \mathrm{~nm}\left({ }^{2} \mathrm{~F}_{7 / 2} \rightarrow{ }^{2} \mathrm{~F}_{5 / 2}\right.$ transition).

As recently reported by some of us, there is a straightforward method to predict the temperature calibration curve of any upconverting thermometer based on two thermally coupled electronic levels independently of the medium. Thermometric systems that must be referred to a well-known temperature for their calibration are classified as secondary thermometers, while primary thermometers are characterized by a wellestablished equation of state that directly relate a measured value to the absolute temperature without the need of calibration $[33,76,77]$. On the other hand, secondary thermometers are quite inexpensive and accessible making them ideal probes for routine temperature measurements. Generally, in secondary thermometers the calibration procedure requires an independent measurement of the temperature to convert the thermometric parameter to temperature. A new calibration procedure is necessary whenever the thermometer operates in a different medium. However, recording multiple calibrations is a time-consuming task, and not always possible to perform, e.g., in living cells and in electronic devices. Primary luminescent thermometers can have overwhelmed the limitation of secondary thermometers as the intrinsic calibration parameter is dependent on well-known quantities and, then, it is computable from other measurements not requiring the material calibration. This is a breakthrough, as tedious and time-consuming calibration procedures become entirely unnecessary if the emission spectra can be measured at a given known temperature. For the illustrative example of $\mathrm{SrF}_{2}: \mathrm{Yb}^{3+} / \mathrm{Er}^{3+}$ doped nanoparticles of distinct sizes and operating in distinct media, Balabhadra et al. [78] defined the thermometric parameter by the usual ${ }^{2} \mathrm{H}_{11 / 2} \rightarrow{ }^{4} \mathrm{I}_{15 / 2}{ }^{4} \mathrm{~S}_{3 / 2} \rightarrow{ }^{4} \mathrm{I}_{15 / 2}$ ratio and compared the temperature measured by an external thermocouple probe (Figure 6.4) with that calculated trough:

$T=\left[\frac{1}{T_{0}}-\frac{k_{B}}{\Delta E} \ln \left(\frac{\Delta}{\Delta_{0}}\right)\right]^{-1}$

where $\Delta_{0}$ is the intensity ratio at a given temperature $T_{0}$. Notice that the energetic separation between the barycenter's of the levels in thermal equilibrium $(\Delta E)$ is calculated applying a deconvolution procedure to the emission spectra. Both calculated and measured temperatures are in excellent agreement as can be attested in ¡Error! No se encuentra el origen de la referencia., opening the possibility to predict the temperature in each situation different of the usual media in which the nanoparticles operate. An obvious application is the use of luminescent upconverting thermometers in biological specimens that generate heat, presents complex biological fluids $(\mathrm{pH}$, ionic 
strength, etc.), thus making this methodology a promising open route to extend the operation range of these materials to several applications.

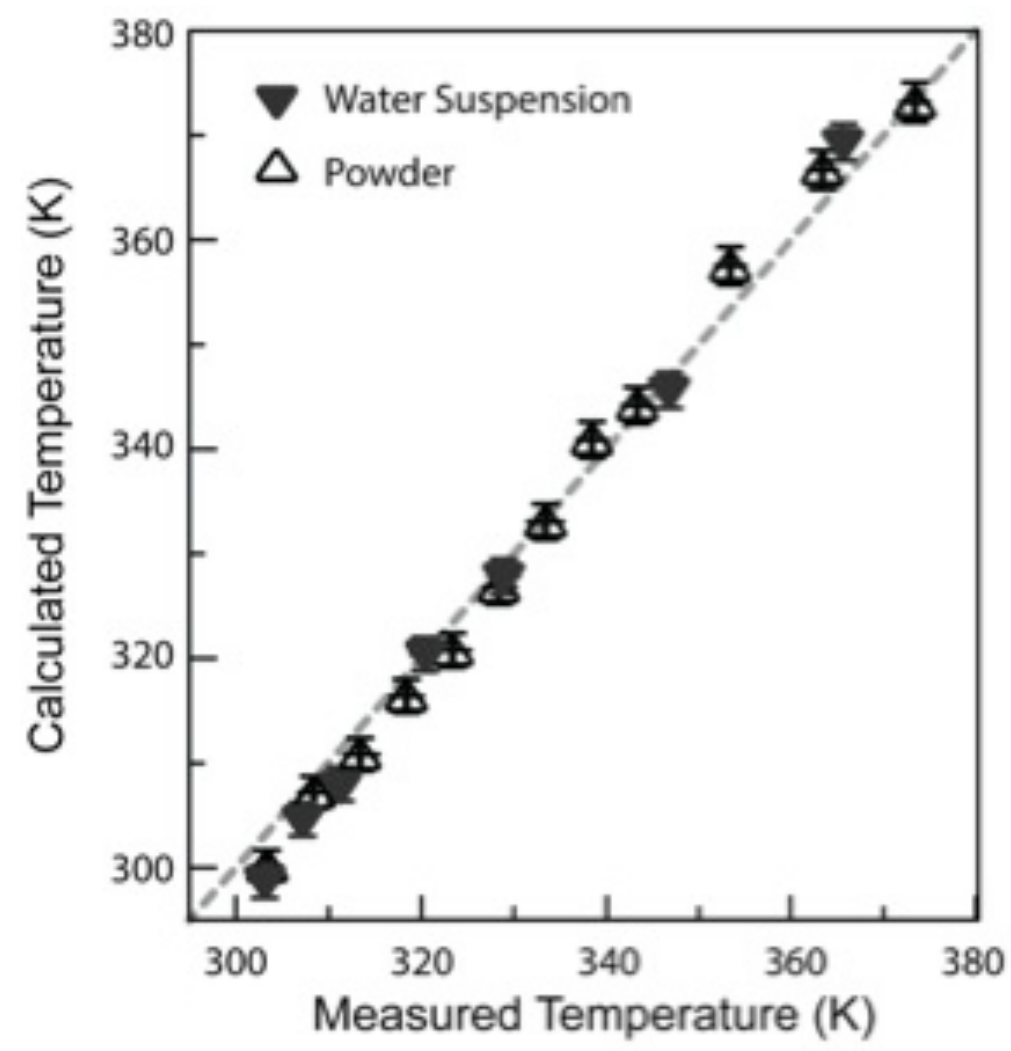

Figure 6.4. Comparison between the temperature values calculated using Eq. 6.2.¡Error! No se encuentra el origen de la referencia. (ordinate) and measured using a thermocouple (abscissa) for $\mathrm{SrF}_{2}: \mathrm{Yb}^{3+} / \mathrm{Er}^{3+}$ nanoparticles in powder and suspended in a water solution. The interrupted line is a guide to the eyes corresponding to a perfect match between the measured and calculated temperatures. Adapted with permission from reference [78].

\subsubsection{Quantifying the thermometer's performance}

It is well accepted that the performance of any thermometer should be quantified to permit the comparison between distinct techniques and among different materials using the same experimental method. The comparison of the performance of distinct luminescence thermometers is made using:

- Relative thermal sensitivity

- Temperature uncertainty (or temperature resolution)

- $\quad$ Spatial and temporal resolution

- Repeatability (or test-retest reliability)

\section{Relative thermal sensitivity}

The relative thermal sensitivity $S_{r}$ indicates the relative change of $\Delta$ per degree of temperature change and is defined as:

$$
S_{r}=\frac{1}{\Delta}\left|\frac{\partial \Delta}{\partial T}\right|
$$


being usually expressed in units of \% change per Kelvin of temperature change $\left(\% \cdot \mathrm{K}^{-1}\right)$. This parameter was introduced in 2003 in the context of optical fiber point temperature sensing [79] and since our initial purpose in 2012 [29] has been commonly used as a figure of merit to compare different thermometers, independently of their nature $[57,58,64,80-83]$. The maximum value of $S_{r}$ is denoted as $S_{m}$. Compared to the absolute sensitivity $S_{a}$ [84],

$$
S_{a}=\frac{\partial \Delta}{\partial T}
$$

$S_{r}$ presents the critical advantage of being independent of the nature of the thermometer (i.e. mechanical, electrical, optical) allowing a direct and quantitative comparison between different samples, a powerful tool when different techniques are considered. Although frequently seen in the literature, $S_{a}$ cannot be used to compare the performance of distinct luminescent thermometers as it depends on the sample characteristics (e.g., absorption and lifetimes) and on the experimental setup.

\section{Temperature uncertainty}

The temperature uncertainty (or temperature resolution) $\delta T$ is the smallest temperature change that can be detected in each measurement:

$$
\delta T=\frac{1}{S_{r}} \frac{\delta \Delta}{\Delta}
$$

being dependent on the thermometer performance (quantified by the relative sensitivity) and experimental setup (that limits $\delta \Delta / \Delta$ ).

\section{Spatial and temporal resolution}

The spatial resolution of a thermometer $(\delta x)$ represents the ability of a given system to resolve temperature changes occurring in two points separated by a certain distance and is defined as the minimum distance between points presenting a temperature difference higher than $\delta T[85]$ :

$$
\delta x=\frac{\delta T}{|\vec{\nabla} T|_{\max }}
$$

where $|\vec{\nabla} T|_{\max }$ denotes the maximum temperature gradient of the mapping. For a onedimensional temperature profile, the temperature gradient is given by

$$
|\vec{\nabla} T|_{\max }=|d T / d x|_{\max }
$$


In analogy to the spatial resolution, the temporal resolution of the measurement $(\delta t)$ is the minimum time interval between measurements presenting a temperature difference higher than $\delta T$ :

$$
\delta t=\frac{\delta T}{|d T / d t|_{\max }}
$$

where $|d T / d t|_{\max }$ is the maximum temperature change per unit of time. Both temporal and spatial resolutions are important to evaluate the applicability of a thermometer for dynamic temperature measurements.

\section{Repeatability}

The repeatability of a thermometer's readout upon temperature cycling is quantified using the expression:

$$
R=1-\frac{\max \left(\left|\Delta_{c}-\Delta_{i}\right|\right)}{\Delta_{c}}
$$

where $\Delta_{c}$ is the mean thermometric parameter (extracted from the calibration curve) and $\Delta_{\mathrm{i}}$ is the value of each measurement of the thermometric parameter. Usually, 10 consecutive measurements are enough to have a minimal statistical significance of the computed results.

\subsubsection{Trends in luminescence thermometry}

In the last couple of years, the focus of luminescence thermometry has gradually shifted from the fabrication of more sensitive nanoarchitectures towards the use of the technique as a tool for thermal bioimaging and for the unveiling of properties of the thermometers themselves and of their local surroundings. Examples in bioimaging are the acquisition of in vivo thermal images [86-88] and ischemia detection in small animals [79]). Concerning thermometers' features, examples are the heat transfer in heater-thermometer nanoplatforms [90], the absorption coefficient and thermal diffusivity of tissues [91], the instantaneous ballistic velocity of Brownian nanocrystals suspended in both aqueous and organic solvents [92], and the thermal conductivity of porous silica and titania nanostructures [93].

Thermal heating of nanoparticles (nanoheaters), induced either by the application of an alternating magnetic field or by irradiation with a near infrared (NIR) laser, has found significant applications in nanomedicine, as, for instance, magnetic hyperthermia (or magnetothermal therapy) [94,95] and photothermal therapy [96-97]. Regarding the last two examples, the accurate measurement of the nanoheaters surface-temperature by a nanothermometer is crucial for regulating the heat released to the surroundings, allowing the adjustment of the irradiation parameters, thus assisting the therapy. Although distinct nanomaterials have been designed and fabricated as nanoheaters for magnetothermal and photothermal therapies [94,95,97,99], single heater-thermometer nanoplatforms operating in the biological spectral windows of the tissues where the absorption of water and biological specimens are minimal, and combining i) efficient light-to-heat or magnetic field-to-heat energy conversion $(>50 \%)$; ii) high relative thermal sensitivity $\left(>1 \% \cdot \mathrm{K}^{-1}\right)$, and iii) low temperature uncertainty $(<0.1 \mathrm{~K})$, have not 
yet been realized, despite the numerous attempts reported in the last five years $[90,100$ $103]$.

To evaluate the heating performance of a suspension of nanoheaters, it is common to use the photothermal conversion efficiency, $\eta$, that is the fraction of the absorbed light converted into heat. The $\eta$ parameter depends only on the particle's properties and can be computed using the time constant method, or using the power ratio method. In the time constant method, a suspension of particles is heated up until reach a constant temperature by absorption of light. Then, the light source is turned off and the temperature decay until the room temperature is followed by a thermocouple. The temperature decay follows an exponential decay to the room temperature with time constant $\tau$. The same experiment is repeated for the solvent used to disperse the nanoheather. Finally, $\eta$ is estimated trough [104]:

$\eta=\frac{m c \Delta T_{\max } / \tau-Q_{s}}{P\left(1-10^{-A}\right)}$

where $m$ and $c$ are the mass and the thermal capacity of the suspension, respectively, $\Delta T_{\max }$ the maximum temperature increase and $\tau$ the time constant of the temperature decay. $Q_{\mathrm{s}}$ is the heat absorbed by the solvent, $P$ is the light source power, and $A$ is the optical density of the suspension (determined by absorbance measurements). Other approach is based on a power ratio, and the $\eta$ is calculated using [105]:

$\eta=\frac{P_{b}-P_{s}}{P_{e}-P_{s}}$

where $P_{\mathrm{b}}, P_{s}$ and $P_{e}$ are the power values measured in an integrating sphere for the solvent, sample and empty sample holder, respectively.

Wawrzynczyk et al., Debasu et al. and Piñol et al. were pioneers in the combination of heat generation and noncontact optical temperature sensing in single nanoplatforms. Whereas heavily $\mathrm{Nd}^{3+}$-doped was used by the first group, the second combines as heater and thermometer (part of the absorbed energy returns to the ground state via nonradiative decays), the second example focus on gold-decorated $\mathrm{NaYF}_{4}: \mathrm{Er}^{3+}$ nanorods in which the system presents plasmonic heating and temperature monitoring using the green emission of the $\mathrm{Er}^{3+}$. Finally, Piñol et al. used a magnetic-luminescent nanoplatform that heats up by means of alternated magnetic field and probes the temperature using the $\mathrm{Eu}^{3+} / \mathrm{Tb}^{3+}$ emissions in the visible range. In the last two examples the thermometer operates out of the first biological window (I-BW, 700-980 nm [88]). Contrarily, $\mathrm{Nd}^{3+}$-based nanostructures can simultaneously generate heating through photothermal conversion and reading temperature using intra- $4 f^{3}$ emissions with energies within the first, second and third biological spectral windows [96,100,106]. However, the relative thermal sensitivity of the $\mathrm{Nd}^{3+}$-based nanostructures (typ. 0.1 $\% \cdot \mathrm{K}^{-1}$ ) is generally one order of magnitude lower than the typical values reported for $\mathrm{Yb}^{3+} / \mathrm{Er}^{3+}$ (typ. $1.0 \% \cdot \mathrm{K}^{-1}$ ) and $\mathrm{Eu}^{3+} / \mathrm{Tb}^{3+}$ (typ. $5 \% \cdot \mathrm{K}^{-1}$ ) luminescent thermometers $[24,99]$.

The comparison between the performances of these nanoplatforms is difficult due to temperature uncertainties and photothermal conversion values scarcely evaluated. For instance, there are only two $\mathrm{Ln}^{3+}$-based examples reporting photothermal conversion 
values: $72.1 \%$ in $\mathrm{NdVO}_{4}$ nanoparticles [107] and $72.7 \%$ in $\mathrm{NaNdF}_{4} @ \mathrm{NaYF}_{4} @ 1 \% \mathrm{Nd}^{3+}: \mathrm{NaYF}_{4}$ multishell nanostructures [108].

Recently, Savchuk et al. [109] reported the $\mathrm{KLu}\left(\mathrm{WO}_{4}\right)_{2}: \mathrm{Ho}^{3+} / \mathrm{Tm}^{3+}$ nanoparticles as new multifunctional heather-thermometer nanoplatforms operating in the I-BW with $S_{\mathrm{r}}=2.8 \% \mathrm{~K}^{-1}, \delta T=0.2 \mathrm{~K}$ (both at $300 \mathrm{~K}$ ) and photothermal efficiency of $34 \pm 2 \%$ [102].

A

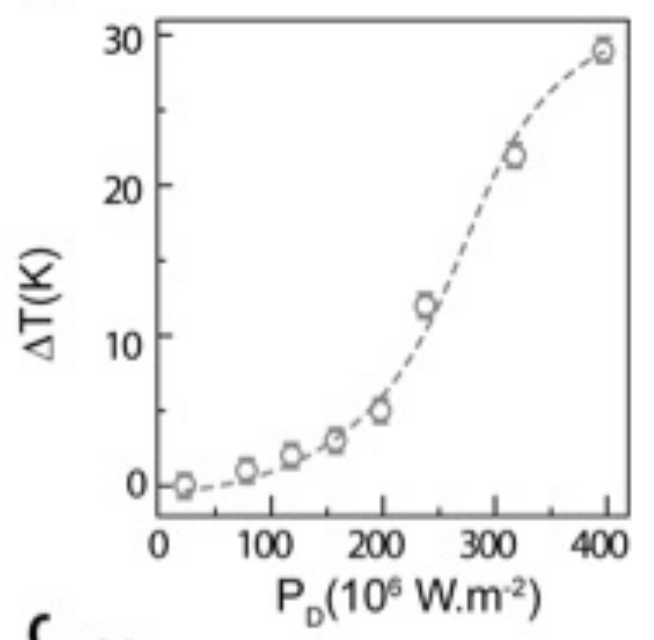

B

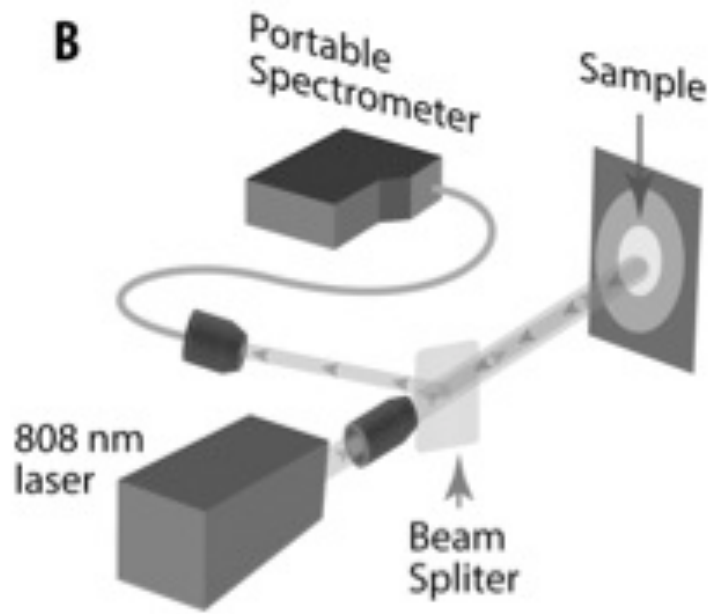

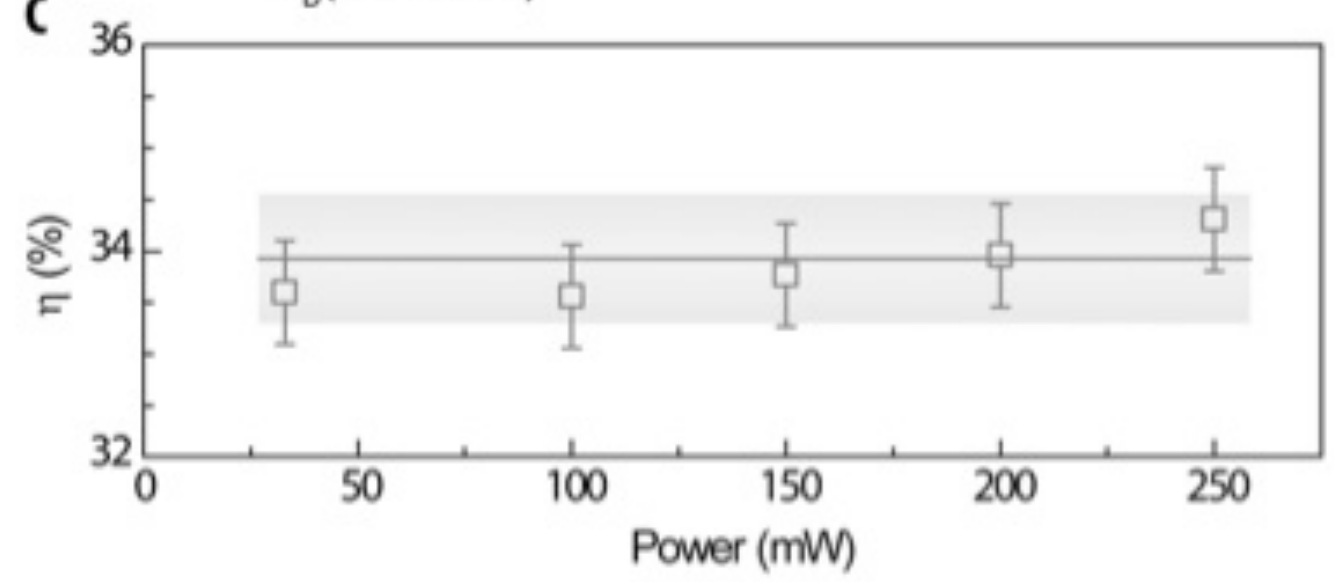

Figure 6.1. (A) Dependence of the temperature increase $(\Delta T)$ with the $808 \mathrm{~nm}$ laser power density $\left(P_{D}\right)$ for the $\mathrm{KLu}\left(\mathrm{WO}_{4}\right)_{2}: \mathrm{Ho}^{3+} / \mathrm{Tm}^{3+}$ nanoparticles. (B) Experimental setup used to estimate the thermal resistance of the nanoparticles. (C) Photothermal conversion efficiency of the nanoparticles upon distinct $808 \mathrm{~nm}$ laser power values. Adapted with permission from reference [109].

The authors used upconversion thermometry to calculate the thermal resistance of the nanoparticles through a full non-contact heating and temperature reading. The thermal resistance of a nanostructured material is a key parameter to understand thermal transport in a large variety of technologies, such as, micro- and nanoelectronics, thinfilm thermoelectric, and nanoparticle-based thermal interface materials [110]. The value obtained by upconversion thermometry for $\mathrm{KLu}\left(\mathrm{WO}_{4}\right)_{2}: \mathrm{Ho}^{3+} / \mathrm{Tm}^{3+}$ nanoparticles, $9.84 \times 10^{7} \mathrm{~K} \cdot \mathrm{W}^{-1}$, is similar than those reported for Si nanorods and Si-based heterostructured nanowires using conventional techniques.

\subsection{Intracellular thermometry}


We have revised in previous sections the state of the art in high-resolution thermometry emphasizing the latest advances in lanthanide luminescent thermometry, which seems especially suitable for nanothermometry in general and cell thermometry in particular. Apart from this feature, high sensitivity in the biological temperature range and fast response are also essential requirements for intracellular thermometry. Moreover, cellular working conditions must also be taken into account such as wide range of $\mathrm{pHs}$ and ionic strengths, low probe concentrations, and local chemical environments. All this features are narrowing the options for intracellular thermometry within the broad scope of nanothermometers available.

In this section, we will revise the systems that have already been tested in cell thermometry. The state of the art is reflected in several recent reviews [29,33,111-113]. From the early work of Chapman et al. in 1995 [114] to 2008 the development of this field has been scarce, however, from then on, the number of publications is increasing exponentially. Being a field with such a young development, it is not strange that most of the proposed cell thermometry systems have been used in proof of concept experiments, and only in a few cases they have been already applied to the study of cell biology processes such as endogenous thermal effects and hyperthermia.

Most of the thermometric systems proposed for intracellular thermometry are noncontact and use optical properties for detection, including: emission intensity, bandshape, bandwidth, lifetime or polarization anisotropy. In many of them the temperature sensing property is directly optical, but in some complex thermometers there is a temperature-sensing property of non-optical character, for instance conformation transition of a thermosensitive polymer, that modifies the emission properties of the optical part [29]. It is important to distinguish between single emission systems that can measure temperature gradients, and multiple emission ratiometric systems that measure absolute temperatures. In the following, we will revise different types of optical materials that are useful for cell thermometry.

\subsubsection{Molecular cell thermometers}

The simplest materials for cell thermometry are organic molecular dyes. They were also the first to be used in cell thermometry [114]. In that early study by Chapman et al. the fluorescent dyes were NBD (7-nitrobenz-2-oxa-1,3-diazo1-4-y1) and laurdan (6dodeca-noy1-2-dimethylamino-naphthalene), the detection parameter was fluorescence lifetime and the sensitivity was just $2^{\circ} \mathrm{C}$. A few years later, Coppeta et al. [115] made a comparative study on the thermometric performance of a series of different dyes (see Figure 6.6. This report shows also a comparison of dual and single fluorophore systems. While dual systems are not affected by variations of excitation light intensity due to absorption, single systems are sensitive to these variations that induce errors in temperature determination (Figure 6.7). The most popular dyes in fluorescence thermometry are fluorescein and rhodamine [116]; however, other dyes such as rosamines can yield higher temperature sensitivities. A rosamine dye, so-called mito thermo yellow, has been tested in several cell lines to determine temperature gradients within the cell when being heated externally with an IR laser beam [117]. Later, it has been used in optical hyperthermia experiments as explained in the next section, whereas other molecular dyes have been used in magnetic hyperthermia [118]. Molecular organic dyes can also be used to fabricate ratiometric thermometers as demonstrated by Homma et al. [119], who attached two different dyes (rhodamine 101 and rhodamine B) by a linker for this purpose, and use it to measure the elevation of temperature in mitochondria. Other types of molecular dyes that have been used in intracellular thermometry are lanthanide coordination compounds [120]. 
The thermometric performance of free dyes can be greatly affected by the cell chemical environment. Therefore it is preferable to use them in encapsulated form, i.e. embedded in a polymer matrix.

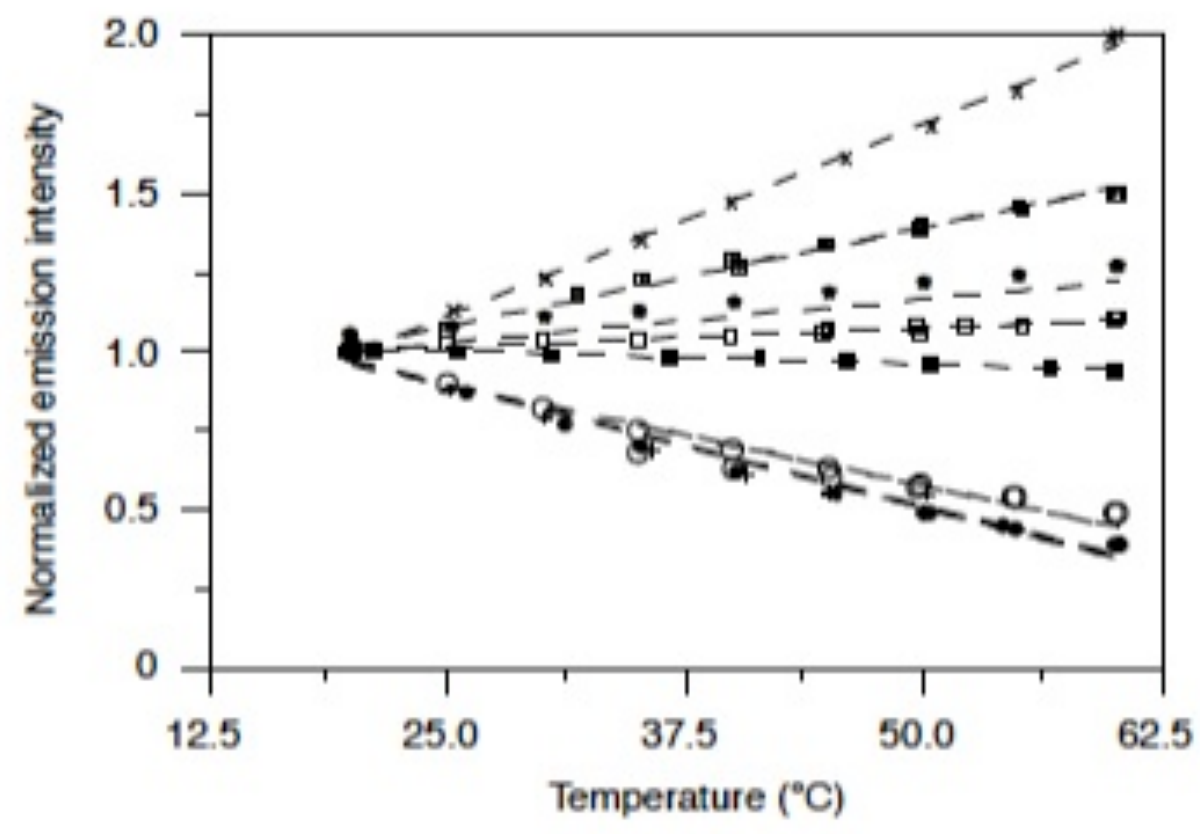

- Phloxine B, Ex:514,Em:590,pH:10

+ Rhodamine B, Ex:514,Em:595,pH:10

- Fluorescein, Ex:488,Em:530,pH:10

- HPTS, Ex:488,Em:530,pH:11

$\square$ Sulforhodamine, Ex:514,Em:630,pH:10

$\times$ Fluorescein, Ex:514,Em:530,pH:10

- Kiton Red, Ex:514,Em:620,pH:10

LDS 698 , Ex:488,Em:680,pH:11.25

Figure 6.6. Variation of the emission intensity of typical organic dyes with the temperature. Reprinted by permission from Springer Nature, ref [115], Copyright 1998. 


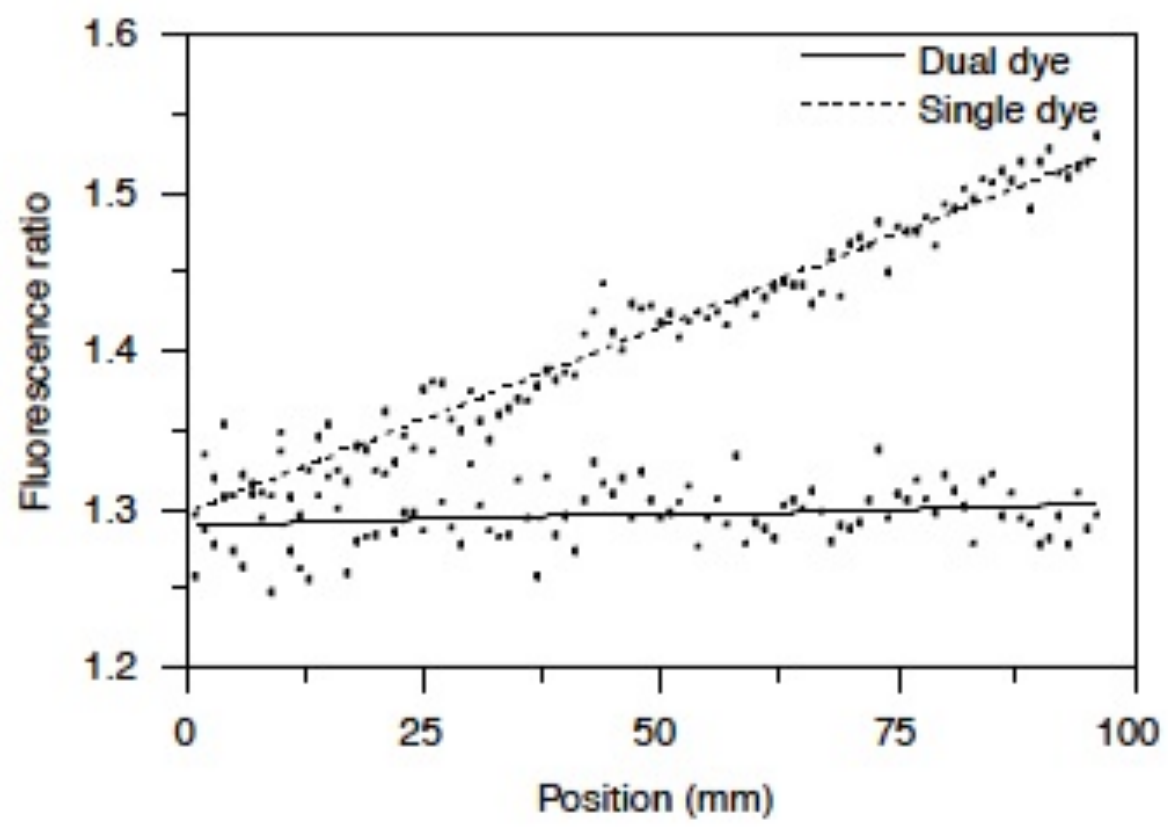

Figure 6.7. Variation of the fluorescence ratio versus position along a line with increasing light absorption for single and dual systems. The dual system is immune to light intensity variation. Reprinted by permission from Springer Nature, ref [115], Copyright 1998.

\subsubsection{Polymer cell thermometers}

A recent review on polymer cell thermometry can be found in ref [121]. In the plainest case of polymer thermometers the role of the polymer is just to act as a protective matrix for molecular thermometric fluorophores. In this system, the preparation of ratiometric thermometers is straightforward and consists on embedding two dyes with different temperature dependence. For instance, a ratiometric nanothermometer has been built by embedding Eu-TTA complex and rhodamine in an amphiphilic copolymer of PMMA (poly(methyl methacrylate)) and PAH (poly- (allylamine) hydrochloride) [122]. This thermometer was used to find the correlation between heat production and $\mathrm{Ca}^{2+}$ dynamics after stimulation with ionomycin.

In a most sophisticated version of polymer intracellular thermometry, the polymer is thermoresponsive and the thermometric sensitivity of the dye is highly potentiated in this way. Moreover, the dye is covalently attached to the backbone of the polymer, directly or within a second polymer that is covalently attached to the first one by block copolymerization. Often, the polymer is also enriched with hydrophilic groups to ensure its stability in water, and may also be crosslinked to form a nanogel [123]. Thermosensitive polymers, undergo swollen to shrinking transitions with increasing temperature that are accompanied with the lost of water, which in turn produce a strong enhancement of the fluorescence of the dye. Thermometric nanogels composed of pNIPAM (poly $(N$-isopropylacrylamide) thermosensitive polymer and a water sensitive dye (DBD, [1,3]dioxolo[4,5-f][1,3]benzodioxole) have been introduced in the cytoplasm of COS7 cells by microinjection and their thermometric response was tested. In this experiments the cell average temperature was obtained by summation of the total intensity collected in all the pixels corresponding to an individual cell. Cell temperature increments of $0.45^{\circ} \mathrm{C}$ were detected after addition of a promoter of mitochondria activity (carbonyl cyanide 4-(trifluoromethoxy)phenylhydrazone (FCCP)). A drawback 
of polymer thermosensitive systems is their narrow working range (from 27 to $33^{\circ} \mathrm{C}$ ) associated to the polymer conformation transition. Based on a block copolymer architecture, Okabe et al. [22] prepared an intracellular thermometer with luminescence lifetime detection. This system yielded temperature maps instead of average temperatures of cells under normal state. The experiments revealed temperature differences of about $1{ }^{\circ} \mathrm{C}$ between nucleus and cytoplasm in COS7 cells, and local temperature gradients associated to mitochondria activity. The thermometric sensitivity was $0.18-0.58^{\circ} \mathrm{C}$, but the working temperature range was also limited to $29-39^{\circ} \mathrm{C}$. This system was further improved by changing the negatively charged hydrophilic block by another with a positive charge that allowed easy cell internalization through cell membrane in HeLa and other mammalian cell lines [124]. The architecture of the copolymer was later modified to include a fourth polymer block containing a dye with a constant intensity of emission independently of the polymer conformation (Figure 6.8), thus obtaining a ratiometric thermometer [125]. Elevating the degree of complexity, $\mathrm{Hu}$ et al. [126] built a block copolymer thermometer formed by a thermosensitive block (NIPAM) and a block containing three monomers each of them holding a different fluorophore: blue-emitting coumarin CM, green-emitting 7-nitro-2,1,3-benzoxadiazole (NBD), and red-emitting rhodamine B. A fluorescence resonance energy transfer (FRET) cascade is established between the three fluorophores, yielding a ratiometric thermometric signal with an improved sensitivity of $0.4^{\circ} \mathrm{C}$ in $20-44^{\circ} \mathrm{C}$ temperature range. Using this thermometer they detected a temperature increment of $0.6^{\circ} \mathrm{C}$ in live HepG2 cells upon glucose treatment.

Another type of intracellular thermometers uses DNA (deoxyribonucleic acid) as the temperature sensitive material and FRET fluorescence as signaling material [127]. DNA strand changes gradually from folded to unfolded conformation and that induce a change in the FRET effect between organic fluorophores (fluorescein and rhodamine) attached to the ends of the strand. The DNA strands are encapsulated in micelles (made with several surfactants). This has been used for preliminary studies in microwaves hyperthermia in cells and mice.

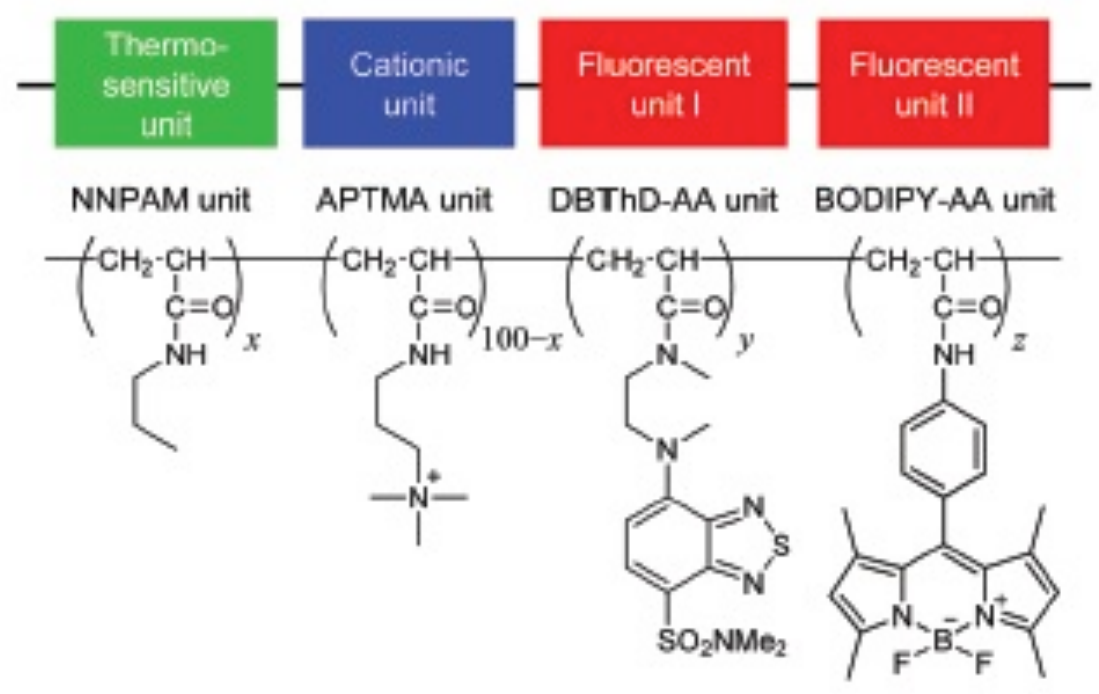

Figure 6.8. A complex construction of ratiometric high sensitivity polymer thermometer. Adapted from ref. 125 with permission from the Royal Society of Chemistry.. 


\subsubsection{Inorganic nanoparticle cell thermometers}

Due to their high brightness, emission stability, temperature dependence emission shifts, and small size, quantum dots are ideal candidates for high spatial resolution temperature imaging. Thus, although there is a strong concern about their toxicity, they have also been proposed as intracellular thermometers. For instance CdSe QDs have been used to map intracellular heat generation in NIH/3T3 cells following $\mathrm{Ca}^{2+}$ stress and cold shock. In this case the thermometric parameter was the spectral shift detected by means of a spectrometer coupled to the microscope [7]. It should be noted that providing the necessary experimental conditions the temperature spatial resolution with these methods could go beyond the diffraction limit to the size of a single QD. A simple way of detection in QDs thermometry based on intensity ratios rather than spectral shifts has been described [8]. The method collects the intensity in two regions at each side of the intensity maximum (650 to 670 , and 630 to $650 \mathrm{~nm}$ ). The ratio of these intensities varies with the temperature as a consequence of the spectral shift. This method can determine the temperature in a single QD, and it has been applied to the study of endogenous heat production of mitochondria (Figure 6.9). Temperature increments of $1{ }^{\circ} \mathrm{C}$ were found after addition of the thermogenesis accelerator, carbonyl cyanide 3-chlorophenylhydrazone (CCCP). It was also used in studies of the temperature distribution in neurons that showed temperature inhomogeneities of $1.7^{\circ} \mathrm{C}$ between neurites and the body of the cell. QD thermometers can also be excited by twophoton-excitation. This method is not only more convenient for using infrared light, which is more penetrating in tissues than visible light, but, it is also more sensitive to temperature and offers a higher spatial resolution than one-photon-excitation in intracellular thermometry [9].

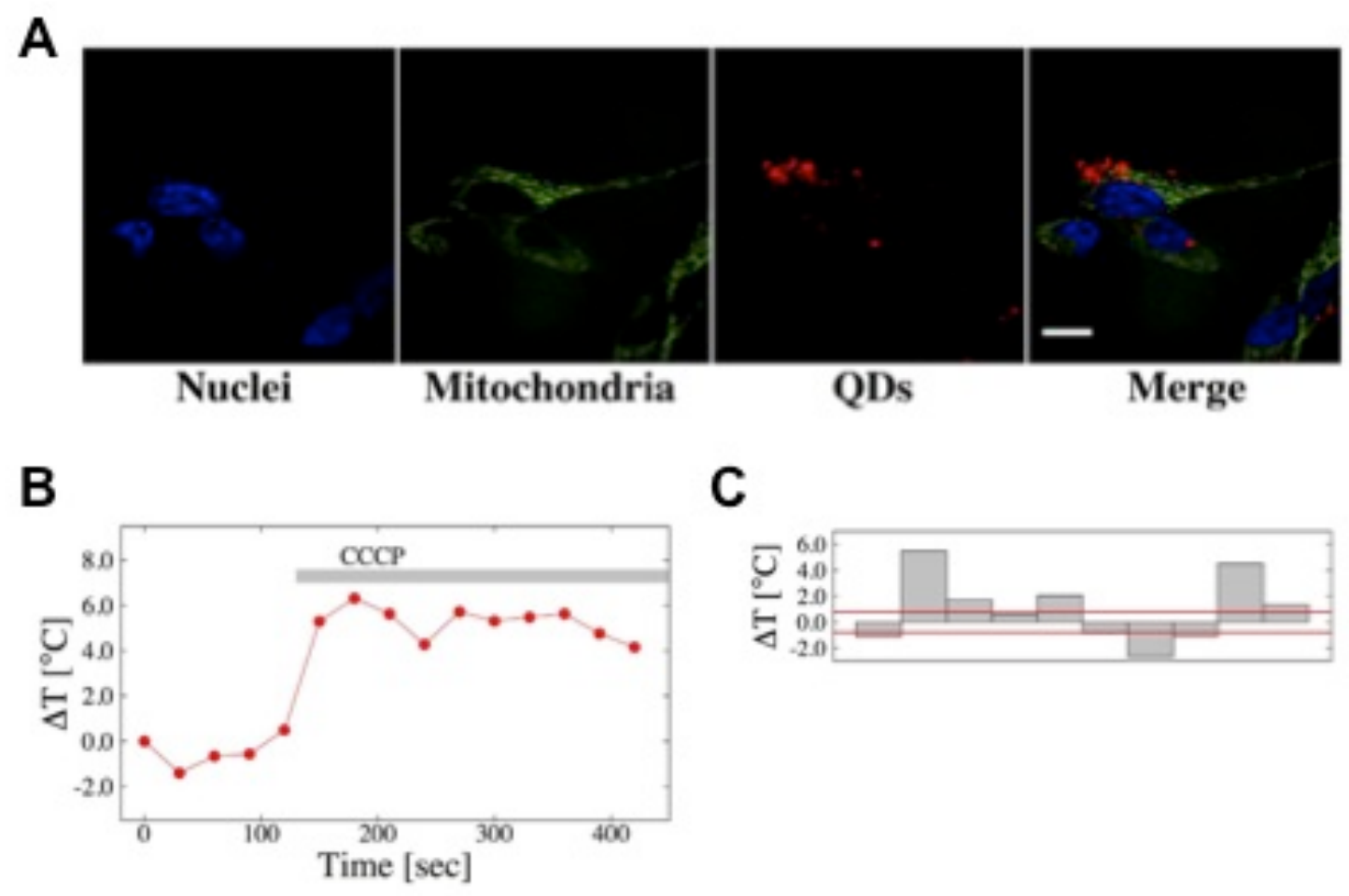

Figure 6.9. Single-QD thermometry in mitochondria. (A) Confocal fluorescence images of living SHSY5Y cells labeling nuclei by Hoechst 33342 (blue) and mitochondria by MitoTracker Green FM (green) and incorporating quantum dots (red). Scale bar 
represents $20 \mu \mathrm{m}$. (B) Representative temperature change of a single quantum dot after carbonyl cyanide 3-chlorophenylhydrazone (CCCP). (C) Summary of temperature change for each measurement. Red lines mark the temperature resolution. Reproduced from ref [8].

Another type of materials that has shown a good capacity for intracellular thermometry is represented by carbon-based NPs such as nanodiamond (ND) [128] and carbon dots (CDs) $[129,130]$. Nanothermometers based on these materials have employed both fluorescence intensity [131] and fluorescence lifetime for detection [130]. CDs have also been combined with gold nanoclusters (NCs) to produce dual-emitting ratiometric thermometers for intracellular thermometry [129]. In its turn, nanothermometry based on nitrogen-vacancy color centers in NDs (which are produced by irradiating diamond with high-energy particle beams), yields an extraordinary sensitivity $(1.8 \mathrm{mK})$ that have been used to evaluate the intracellular temperature gradients produced by optical hyperthermia with AuNPs, as described in section 6.5.

Realizing the importance of local temperature on the functioning of cell organelles, Wei et al. [132] proposed a dual emission combination of carbon dots (CDs) and a fluorescence dye (rhodamine) as intracellular thermometer and showed its response in cells submitted to temperature changes from 5 to $50^{\circ} \mathrm{C}$ degrees. The ratiometric temperature sensing was based on a different temperature dependence of CDs $(480 \mathrm{~nm}$, low) and Dye (580 nm, high) emissions.

Another nanothermometer with a very small size that has been proposed for intracellular thermometry is based on $\mathrm{Au}$ nanoclusters (NCs) that show a lifetime emission dependence with temperature in the $710 \mathrm{~nm}$ emission band under $580 \mathrm{~nm}$ excitation [133].

Especially suitable for deep tissue thermometry [11], upconverting nanoparticles (UCNPs) are also useful for cell thermometry. As explained in previous section the differential feature in these luminescent NPs is that they can be excited with a lower energy radiation (IR) than the emission energy (VIS or IR), and thus they can work in biologically transparent window [33,11]. They consist on different types of inorganic crystals hosting a sensitizer ion (usually $\mathrm{Yb}^{3+}$ ) that transfers the energy in a double or triple photon process to a sensitizer ion (also a lanthanide) that release this energy by luminescence radiation at a shorter wavelength. Based on this system, Vetrone et al. [60] measured the intracellular temperature of HeLa cervical cancer cells from $25^{\circ} \mathrm{C}$ to its thermally induced death at $45^{\circ} \mathrm{C}$. The UCNPs ratiometric thermometer was made of $\mathrm{NaYF}_{4}$ nanoparticles doped with $\mathrm{Er}^{3+}$ and $\mathrm{Yb}^{3+}$, and it worked with $980 \mathrm{~nm}$ excitation wavelength and $525 \mathrm{~nm}$ and $545 \mathrm{~nm}$ emission wavelengths.

\subsubsection{Organic-inorganic hybrids cell thermometry}

Nanothermometers can also be built with Hybrid-Organic-Inorganic (HIO) materials [134] and they have demonstrated their utility for cell thermometry. There are several types of HIO nanothermometers including molecular hybrids (discrete metal-organic molecular compounds, layered double hydroxides, and metal-organic frameworks), polymer nanocomposites, and core-shell nanoparticles. As remarked above for molecule-based thermometry, a simple case is that in which the organic phase is just acting as protective matrix. For example, ultrabright nanothermometers have been built by embedding CdSe/ZnS QDs in a PMMA-co-MAA (polymethylmethacrylate-comethacrylic acid) copolymer matrix [135]. This thermometer was applied to follow temperature increments in different regions in cells under IR laser heating. This is also the case of hybrid nanostructures formed by neodymium (III)-doped $\mathrm{NaGdF}_{4}$ dielectric 
nanoparticles (NPs) and semiconductor $\mathrm{PbS} / \mathrm{CdS} / \mathrm{ZnS}$ quantum dots (QDs) encapsulated in poly(lactic-co-glycolic acid) (PLGA) nanobeads [135]. Both Nd-doped-NPs and QDs emit in the IR biological window so they have a high penetration in tissue. Their responses to temperature changes are different being more pronounced in the second case, so their combination makes a ratiometric thermometer. This system and similar ones have demonstrated to be effective for temperature mapping in cells [83] and tissues [136]. The polymer can also play a role in temperature sensing (see Figure 6.10), an example is that of a ratiometric hybrid thermometer in which Au NCs were embedded in a temperature responsive copolymer [137]. This strategy is similar to that of Okabe et al. [22] using molecular fluorophores, but this time, one of the emitters is inorganic (AuNC) an the polymer is an alternating (instead of block) copolymer (P(NIPAMNBD-NSVB)) comprising 3 different monomers: one with the temperature responsive property (NIPAM), another carrying a fluorophore dye (NBDAA, 4-(2acryloylaminoethylamino)-7-nitro- 2,1,3-benzoxadiazole), and a third one holding a protein linkage group (NSVB, N-Succinimide p-Vinylbenzoate). This system was used to investigate the cell temperature after ionomycin calcium complex solution treatment. Average cell temperature increments of $4-5^{\circ} \mathrm{C}$ were recorded after the treatment.

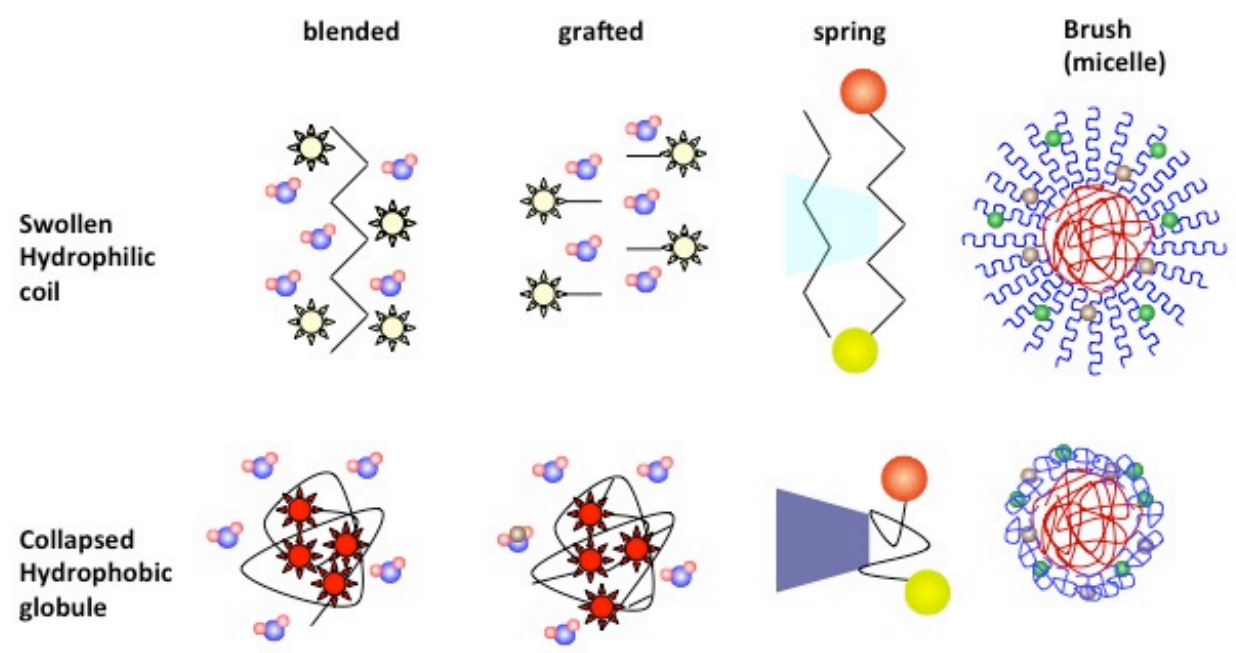

Figure 6.10. Different arrangements of chromophors in polymer nanocomposite nanothermometers. Reproduced from ref. 29 with permission from The Royal Society of Chemistry.

\subsubsection{Endogenous fluorescence cell thermometers}

A class apart of non-invasive intracellular thermometers is that of endogenous genetically encoded fluorescent proteins. Enhanced Green Fluorescent Protein (EGFP) shows a variation of the fluorescence emission intensity at 515-520 nm when excited at $473 \mathrm{~nm}$, in the region from $20^{\circ} \mathrm{C}$ to $60^{\circ} \mathrm{C}$ [138]. The expression of EGP can be induced 
by a careful application of IR-LEGO (Infrared Laser-Evoked Gene Operator) laser to avoid cell death. This system has tested in vitro (bacteria) and in vivo (Caenorhabditis elegans). Other authors [20] using GFP (Green Fluorescent Protein) proposed fluorescence polarization anisotropy instead of intensity as a more robust thermometric parameter, thus reaching $0.4^{\circ} \mathrm{C}$ accuracy in a confocal microscope. However, the measuring time for a single cell monitoring was in the range of minutes. Kiyonaka et al. [139] built a fluorescence intensity ratiometric thermometer by tandem formations of GFPs and TlpA protein, which undergoes conformational changes with temperature that are transmitted to GFP, thus enhancing the thermometric response of this protein. The working mechanism is based on changes in the excitation peaks at $400 \mathrm{~nm}$ and $480 \mathrm{~nm}$ for a $510 \mathrm{~nm}$ emission wavelength. In this way, they could visualize thermogenesis phenomena in the cell membrane, the mitochondria and the endoplasmic reticulum.

Recently another genetically encoded ratiometric fluorescent thermometer has been reported [140] based on two fluorescent proteins, mT-Sapphire and Sirius, with different temperature sensitivities. mT-Sapphire has a little temperature dependence of emission at $425 \mathrm{~nm}$, whereas Sirius shows a strong temperature variation of emission at $509 \mathrm{~nm}$. The detection system uses a beam splitter to capture the dual luminescence from the two-protein complex. This method has been employed to measure temperature heterogeneities among cell organelles (Figure 6.11). Temperature increments of $6-9^{\circ} \mathrm{C}$ were found in the interior of mitochondria under chemical stimulation with carbonyl cyanide 4(trifluoromethoxy)phenylhydrazone. Notice that previous measurements of the outside temperature yielded $1{ }^{\circ} \mathrm{C}$, suggesting a relatively high temperature gradient inside the mitochondria. They also found a $2.9^{\circ} \mathrm{C}$ temperature gradient between nucleus and cytoplasm in live HeLa cells.

Within this kind of endogenous thermometers, we can also mention the case of temperature-sensitive mutations [141]. The mutants show a temperature-dependent transcription of enzymes that, after a cascade of reactions provoke the apparition of colored or fluorescent molecules. A system of this type based on LacI(Ts) (lactoseinduced(thermosensitive)) regulated expression was tested in E. coli cells yielding a sensitivity of $0.7^{\circ} \mathrm{C}$ in a 35 to $45^{\circ} \mathrm{C}$ temperature range. 

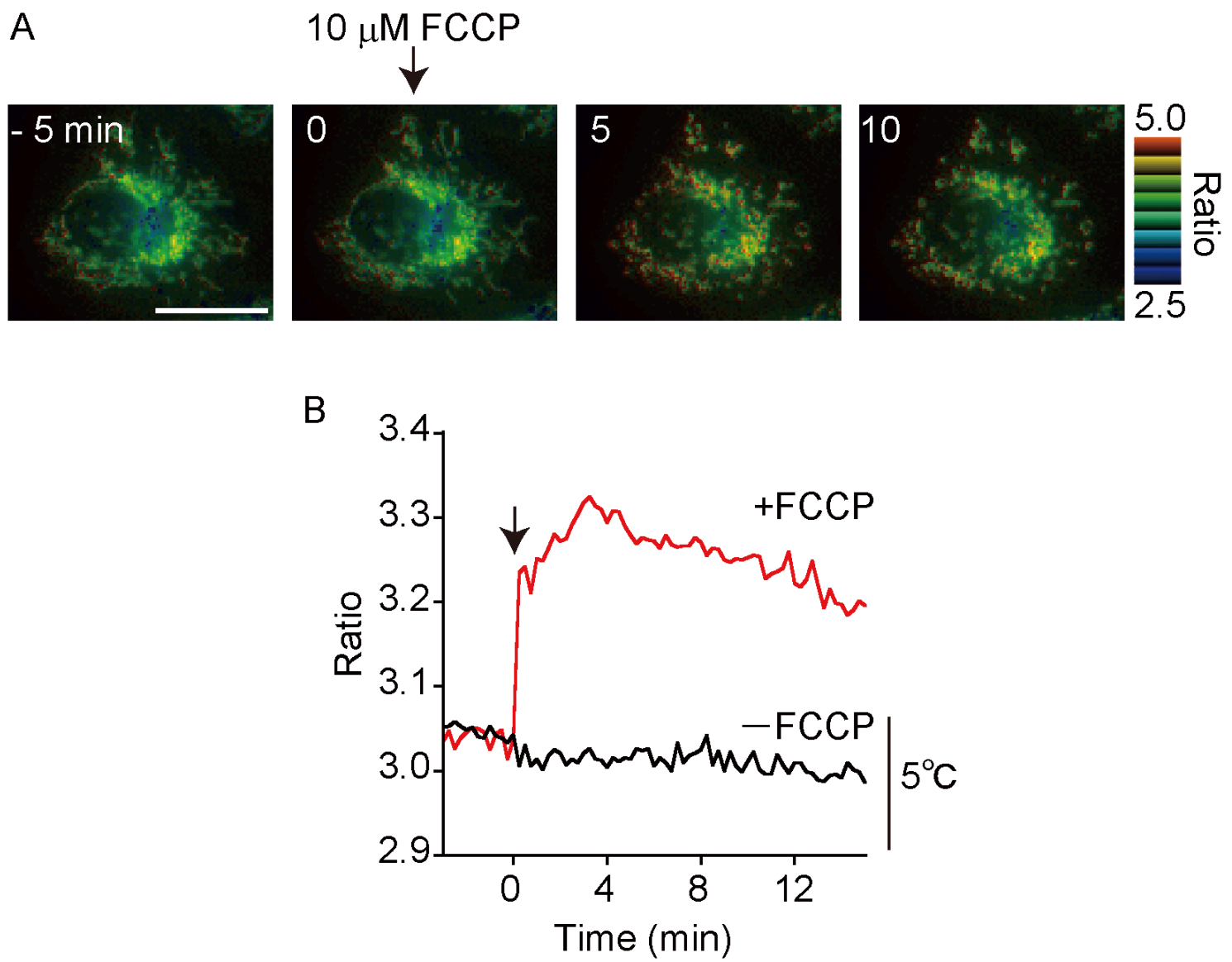

Figure 6.11. Monitoring temperature change in mitochondria. (A) Pseudo-colored ratio image of gTEMP (genetically encoded ratiometric fluorescent temperature indicator) expressed in mitochondria of a HeLa cell upon FCCP (carbonyl cyanide 4(trifluoromethoxy)phenylhydrazone) stimulation. At time $=0 \mathrm{~min}, 10 \mu \mathrm{M} \mathrm{FCCP}$ was added to the cell. (B) Time course of the ratio in mitochondria with FCCP and without FCCP. Reproduced from ref [140].

\subsubsection{Cellular contact thermometry}

Finally, contact thermometry has also been proposed as an alternative for cell thermometry. For instance, the surface temperature of fixed cells has been mapped with thermocouple microarrays [142]. Obviously, these methods do not give the real intracellular temperature that should be estimated after considering heat conduction effects at the nanoscale that are not well known and can be quite relevant in cellular systems. Using this microarray system, adherent human hepatoblastoma (HepG2) cells were screened for periods of several days showing frequent fluctuations within $60 \mathrm{mK}$ and a maximum increment by $285 \mathrm{mK}$. Another contact thermometer proposed for intracellular thermometry is based in the use of a micropipette filled with a lanthanide coordination compound ( $\mathrm{Eu}^{3+}$-TTA) that was placed in contact with the cell [143]. The authors observed the thermogenesis generated by ionomycin-induced $\mathrm{Ca}^{2+}$ influx in HeLa with this system.

\subsection{Intracellular thermometry for hyperthermia studies}

In general, intracellular thermometry for hyperthermia studies has followed two strategies: 1) dual-particle approach, in which heating and thermometry are carried out using two independent nanoparticles, and 2) single-particle approach, in which the temperature sensing elements are incorporated into the heating nanoparticle structure. 
The dual-particle approach offers a wide scope of choices for temperature screening in hyperthermia studies. In principle, all the systems described in the previous section could be applied. However, this approach does not yield a direct value of the nanoheater temperature, and this has to be estimated from heat transfer models. Actual models have a contrasted precision in macroscopic systems, but they might not be so accurate at the nanoscale [90]. Moreover, the distances between nanoheaters and nanothermometers within the cell cannot be controlled in these systems $[144,128]$. These problems may be partially alleviated by incorporation of the heating and sensing nanoparticles in a common nanoparticle matrix [101]. Nevertheless, local temperatures can be very important as they may induce thermal degradation of biomolecules in the vicinities of the nanoheaters leading to cell apoptosis processes, without significant temperature changes in the cytoplasm, as pointed out in the introduction section. Therefore, it is desirable to have thermometry data at the precise localization of the nanoheathers, which can only be attainable with the single-particle approach. To this respect, the ideal situation would be to have a single system for heating and thermometry. There are systems in optical hyperthermia that are close to this ideal situation [96,103]. On the other hand, optical hyperthermia and magnetic hyperthermia present peculiarities that make the application of cell thermometry a distinct challenge for each case, so they will be treated in two different subsections.

\subsubsection{Intracellular thermometry in optical hyperthermia}

Heat power of NPs in optical hyperthermia, especially that based on plasmonic resonance of AuNPs, is orders of magnitude higher than that attainable in magnetic hyperthermia. Thus, it is not surprising that most of cell thermometry studies on hyperthermia effects have been dedicated to this type of hyperthermia, because the thermal effects are stronger and easier to observe.

Early reports of thermal studies on cell optical hyperthermia were authored by Donner et al. [145]. They were performed on HeLa and U-87 MG cancer cells using endogenous cell thermometric probes (GFP) and fluorescence anisotropy detection. GFP molecules were excited with a blue laser $(\lambda=473 \mathrm{~nm})$. Temperature increase was induced by local photoheating of gold nanorods (GNRs) located in the extracellular cell media or internalized under irradiation with a laser wavelength set at $800 \mathrm{~nm}$. This system was later used to image plasmonic heating in a living organism [146]. Optical hyperthermia experiments with AuNPs with the purpose to stimulate muscles were followed using mito thermo yellow molecular thermometer [147]. These studies revealed interesting phenomena associated to photothermal stimulation such as an increase of mRNA (messenger RNA) transcription of genes encoding heat shock proteins and sirtuin, which can induce mitochondrial biogenesis.

\subsubsection{Dual-particle systems}

Using the dual-particle approach, Yang et al. [148] followed the intracellular temperature of HePG2 cells under plasmonic-based photothermal treatment (PPT). The heat sources were $\mathrm{Au}$ nanorods coated with PEG (polyethylene glycol), and the temperature probes were silica nanoparticles doped with luminescent $\mathrm{Ru}(\mathrm{bpy})_{3}{ }^{2+}$ molecules. The sensitivity of the thermometric system was $1.26 \%{ }^{\circ} \mathrm{C}^{-1}$, in a $25-45^{\circ} \mathrm{C}$ temperature range, with a $450 \mathrm{~nm}$ excitation and 550-650 $\mathrm{nm}$ emission wavelengths. Fluorescence intensity maps from the thermometric emission were recorded that showed a variation of the intracellular temperature when the $\mathrm{Au}$ nanorods were irradiated with a $808 \mathrm{~nm}$ laser (Figure 6.12). 
Kucsko et al. [128] used nanodiamonds to follow the heating of AuNPs under laser irradiation. The measurements were used to evaluate the intracellular temperature gradients produced by optical hyperthermia with AuNPs. Temperature gradients at the heat source location were estimated from the measured temperatures in NDs at several distances from the source. Estimated gradients of $80^{\circ} \mathrm{C}$ were observed with a high laser intensity that caused cell death, but at low laser intensities producing $10^{\circ} \mathrm{C}$ gradients the cells survived.
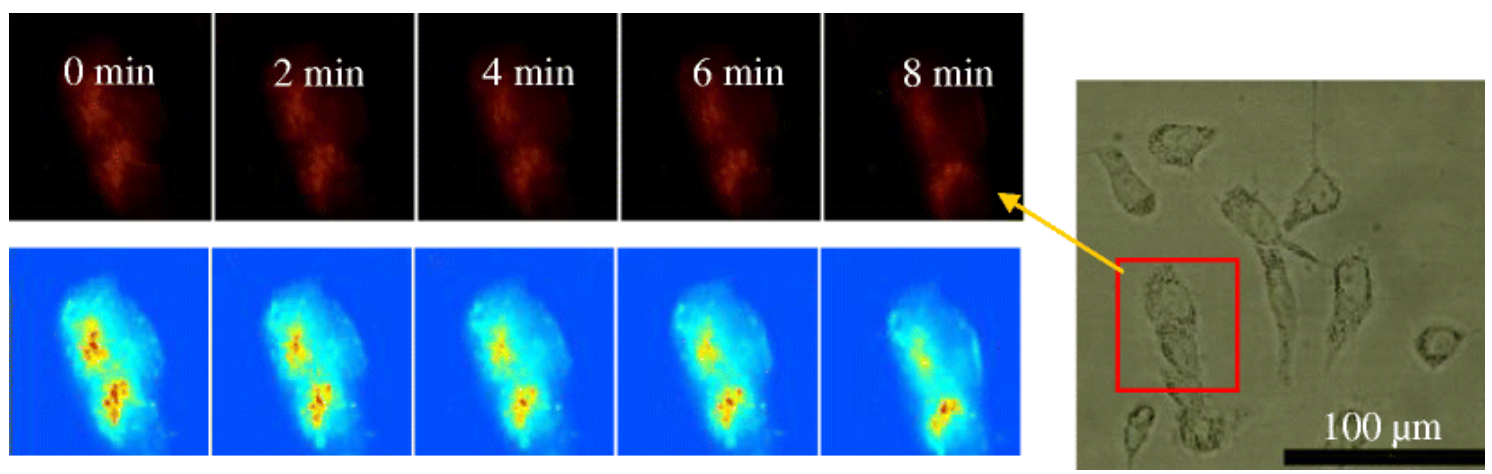

Figure 6.12 Luminescence images (top left side) and corresponding pseudo color luminescence intensity images (down left side) of HePG2 cells taken after different times of irradiation with $808 \mathrm{~nm}$ light. On the right side, bright field image (BF) of the cells after internalization of the coated AuNRs. Blue in the pseudocolor images corresponds to a decrease of the luminescence intensity. Reprinted by permission from Springer Nature, ref [148], Copyright 2014.

Another cell thermometry experiment based on dual-particle system has been reported by Maestro et al. [144]. The thermometric NPs were PEG coated QDs (CdSe), and the heathers were gold nanorods capped with cetyltrimethylammonium bromide bilayer. The thermometric detection parameter was the shift of the emission maxima at $650 \mathrm{~nm}$ under $488 \mathrm{~nm}$ excitation (sensitivity $=0.16 \mathrm{~nm} /{ }^{\circ} \mathrm{C}$ ). The heating of AuNRs was induced by $808 \mathrm{~nm}$ laser irradiation. Controlled hyperthermia experiments were conducted in a double-beam confocal microscope in HeLa cells. Temperature increments of $3^{\circ} \mathrm{C}$ were observed, together with drastic cell morphology changes indicative of cell death, under relatively low power irradiation $(4 \mathrm{~mW})$. When the power intensity was raised to 7.5 $\mathrm{mW}$, the cell temperature increased $5.5^{\circ} \mathrm{C}$ and cell death was massive. Thermal-induced morphological changes were also observed on non-irradiated surrounding cells attributed to temperature diffusion effects. In another experiment from the same group [149], the temperature on the cells surroundings was determined using a $\mathrm{NaYF}_{4}: \mathrm{Er}^{3+}, \mathrm{Yb}^{3+}$ upconversion microparticles as thermometric probes. This thermometric system is ratiometric $\left(\mathrm{I}_{540} / \mathrm{I}_{525}\right)$ and yields a very high sensitivity $\left(1.6 \times 10^{-2}\right.$ $\pm 0.1 \times 10^{-2}{ }^{\circ} \mathrm{C}^{-1}$ at $\left.25^{\circ} \mathrm{C}\right)$. With a clever combination of optical trapping to displace a single microcrystal and luminescent thermometry on this microcrystal, the temperature at the cell surroundings was precisely scanned (see Figure 6.13). Significant temperature increments were measured in the cell surroundings that increased with the laser power (irradiating the AuNRs) up to $15^{\circ} \mathrm{C}$, when the power was $72 \mathrm{~mW}$. The increment reduced to a half at $6 \mu \mathrm{m}$ from the cell, and reduced to zero at $6 \mu \mathrm{m}$. Therefore, it was conclude that cell hyperthermia treatment with AuNRs will affect also to surrounding cells.

The same group [150] studied the heating efficiency of multi-walled carbon nanotubes (MWCNTs) under optical excitation within the first $(808 \mathrm{~nm})$ and second $(1090 \mathrm{~nm})$ 
biological windows. The thermometric system was the same as the one used in ref [144] for GNRs. MWCNTs showed lower heat power than GNRs, however the power was wavelength independent in the 800-1100 $\mathrm{nm}$ range, whereas that of GNRs decreases rapidly when shifting from surface plasmon absorption maximum.
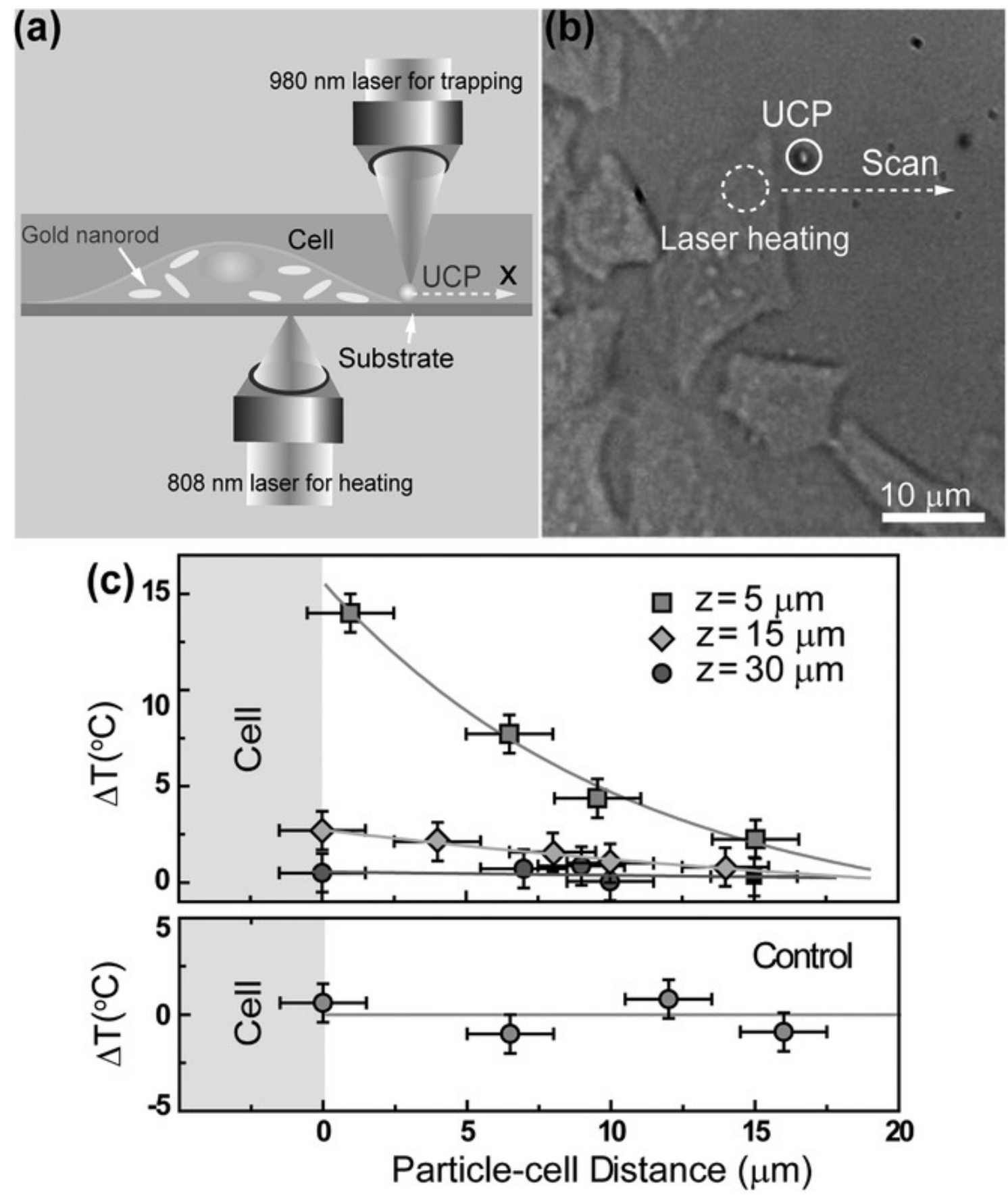

Figure 6.13. a) Schematic representation of the experimental setup used for thermal scanning in the surroundings of a HeLa cell subjected to a plasmonic mediated photothermal treatment. The thermal scan direction is indicated with an arrow. b) The optical-transmission image of the HeLa cancer cells after incubation with GNRs. The dashed circle indicates the position of the (heating) $800 \mathrm{~nm}$ laser spot. The presence of the $\mathrm{NaYF}_{4}: \mathrm{Er}^{3+}, \mathrm{Yb}^{3+}$ particle used for thermal measurements is also indicated by a dashed circle. c) Upper part: Temperature decay measured from cell surface for three heights (distances from substrate). The symbols are the experimental data, and the lines 
are guides for the eyes. Lower part: Control thermal scan performed in absence of the $800 \mathrm{~nm}$ heating laser. Reproduced with permission from John Wiley and Sons, ref [149].

High-resolution thermal sensing is not only interesting at the cellular level but also in animal models, which are more useful in diagnosis and controlled hyperthermia treatment. Whereas outstanding results has been obtained with visible emitting lanthanides regarding in vitro studies, their application for in vivo studies is restricted due to the low penetration depth of visible light in the tissues. To overcome this restriction, a great effort has been made to develop materials whose bands of emission and absorption are found within the so-called biological windows where the dispersion and absorption of tissues are minimized. Two biological windows are typically defined; the first and second (I-BW and II-BW) correspond to the spectral ranges of 650-950 and 1000-1350 nm. Rocha and co-workers [102] carried out single-beam subtissue optical hyperthermia treatments by combination of GNRs $\left(45 \times 15 \mathrm{~nm}^{2}\right)$ nanoheathers and $\mathrm{Nd}^{3+}$ doped $\mathrm{LaF}_{3}$ (core)/undoped $\mathrm{LaF}_{3}$ (shell) NPs that act as nanothermometers and nanoheaters under $808 \mathrm{~nm}$ continuous wave excitation. The optimum excitation of the $\mathrm{Nd}^{3+}: \mathrm{LaF}_{3}$ are also coincident with the most efficient wavelength for the plasmon resonance used for photothermal therapies of GNRS. Temperature variations within the biological range have been found to cause linear modifications in both the spectral position of emission lines as well as on the relative intensities $\mathrm{Nd}^{3+}$ emission lines to display a remarkable luminescence thermal sensitivity with a value of $\left(2^{\circ} \mathrm{C}\right)$. For the determination of subtissue imaging and temperature sensing, the spectral position of the characteristic bands of $\mathrm{Nd}^{3+}$ ions at around 900 and $1060 \mathrm{~nm}$ (corresponding to the ${ }^{4} \mathrm{~F}_{3 / 2}$ $\rightarrow{ }^{4} \mathrm{I}_{9 / 2}$ and ${ }^{4} \mathrm{~F}^{3 / 2} \rightarrow{ }^{4} \mathrm{I}_{11 / 2}$ transitions respectively) bands is especially favorable. They match well the extinction coefficients minima of human tissues within the biological windows.

\subsubsection{Single-particle systems}

An easy construction for single-particle nano-heather-thermometer consists in embedding organic fluorescents dyes in the shell of polymer-coated nanoheathers. Freddi et al. [151] used this strategy with gold nanorods and gold nanostars optical nanoheathers, and also with iron oxide magnetic nanoheaters. The thermometric dye was positively charged rhodamine $\mathrm{B}$ that was absorbed by electrostatic forces on the negatively charged polymer shell surface. A layer-by-layer coating with negative (PAH) and positive (poly(sodium 4-styrenesulfonate, PSS) polyelectrolytes permits to regulate the thickness of the coating and therefore the distance from the thermometric probe to the heat source. The temperature detection parameter was emission lifetime with a sensitivity of $0.029 \pm 0.001 \mathrm{~ns} /{ }^{\circ} \mathrm{C}$ and an uncertainty of $0.3^{\circ} \mathrm{C}$. Strong heating efficiency decay was observed at a $6.5-8.5 \mathrm{~nm}$ distance. The system permitted to compare the heat power of the different nanoheathers in aqueous suspension. Heat powers (specific absorption rate, SAR) of 430 and $190 \mathrm{~kW} / \mathrm{g}$ were estimated for gold nanorods and nanostars, respectively, for a $13 \mathrm{~W} / \mathrm{cm}^{2}$ laser power. The SAR of magnetic nanoparticles was orders of magnitude lower $(0.2 \mathrm{~kW} / \mathrm{g}$, for a $168 \mathrm{kHz}, 32 \mathrm{mT}$ ac magnetic field). The system was proposed for cell hyperthermia, but it was only tested in aqueous suspensions.

A similar construction of surface attached thermometers was used by Nigoghossian et al. [152], only that this time, the heating component was in the nanoparticle shell, and the thermometric probe was a core nanoparticle instead of a molecular dye. The heaters were gold coated silica nanoparticles (gold nanoshells, with a size of $283 \mathrm{~nm}$ ), and the 
thermometric nanoparticles were $\mathrm{NaGdF}_{4}: \mathrm{Yb}^{3+}: \mathrm{Er}^{3+}$ upconversion nanoparticles (D = $25 \mathrm{~nm}$ ) coated with a $7 \mathrm{~nm}$ silica layer. The surface of the thermometric nanoparticles was modified with amine groups so they could bind to the gold surface. The temperature sensitivity was higher than $3 \times 10^{-3} \mathrm{~K}^{-1}$ in a $20-70^{\circ} \mathrm{C}$ temperature range. Temperature increments of $19^{\circ} \mathrm{C}$ for a $0.2 \mathrm{~W}$ laser power were recorded in an aqueous nanoparticle suspension. However, the system was not tested in cells.

Debasu et al. [101] reverted the disposition of nanoheaters and nanothermometers, using thermometric $(\mathrm{Gd}, \mathrm{Yb}, \mathrm{Er})_{2} \mathrm{O}_{3}$ nanorods as the central core and gold nanoheaters as surface decoration. However, the thermometric probe was over-sized relative to the heater and the laser excitation was off-resonance. This system was later improved by using gold nanorods with a similar size than the thermometric nanorods and a polyelectrolyte PSS polymer spacer linking between the nanoparticles [153]. The system showed a thermal sensitivity of $1.22 \%{ }^{\circ} \mathrm{C}^{-1}$ at $29^{\circ} \mathrm{C}$ with and a $0.32^{\circ} \mathrm{C}$ uncertainty. Cell toxicity was assayed on MG-63 and A549 cells, but hyperthermia experiments were not carried out. Instead of surface linking, Rocha et al., [154] embedded the heater nanoparticles (gold nanorods) and $\mathrm{Nd}$ doped $\mathrm{LaF}_{3}$ nanoparticles in a PLGA polymer shell (hydrodynamic diameter, $\mathrm{D}_{\mathrm{h}}=120 \mathrm{~nm}$ ). Both the heater and the thermometer were excited with the same $790 \mathrm{~nm}$ laser beam. The $\mathrm{LaF}_{3}: \mathrm{Nd}^{3+}$ thermometer is ratiometric $\left(\mathrm{I}_{863} / \mathrm{I}_{886}\right)$. The dual system was successfully tested in chicken breast tissue at a depth of $2 \mathrm{~mm}$. Temperature gradients between heaters and surface temperatures were registered during laser radiation.

Similar polymer embedding strategies of both nanoheaters and nanothermometers have been used by del Rosal et al. [155]. In this case, the polymer matrix was poly(lactic- $c o$ -glycolic acid) (PLGA), the thermometric probes were $\mathrm{Nd}^{3+}$ doped $\mathrm{NaGdF}_{4}$ nanoparticles, and the heathers were $\mathrm{PbS} / \mathrm{CdS} / \mathrm{ZnS}$ quantum dots. Although having a moderate photothermal efficiency compared to gold nanostructures, these QDs nanoheaters can lead to temperature increments as high as $45^{\circ} \mathrm{C} 808 \mathrm{~nm}$ laser at $1.7-2$ $\mathrm{W} \mathrm{cm}{ }^{-2}$ as it has been shown in ex vivo and in vivo experiments.

The examples described above correspond to systems where the bioimaging, heating and temperature sensing capacities are performed by two different components incorporated in a single nanoplatform. In a step forward towards improving the local temperature measurement some research follow a different approach in which "single NPs" incorporate all the functionalities. A good example of this has been realized by Rocha et al. [96] in the form of $\mathrm{Nd}^{3+}$ doped $\mathrm{LaF}_{3}$ nanoparticles with a high $\mathrm{Nd}^{3+}$ content (up to 25\%) This system is capable of simultaneous photo thermal treatment and temperature mapping by irradiation with a single near infrared laser beam $(808 \mathrm{~nm})$. The ratiometric thermometry parameter is obviously similar to the former case. In vivo experiments revealed a significant temperature increase that is $60 \%$ higher in the injection site with respect to the tissue surface. Another case of joining heating and thermometry in a unique compound has been recently reported by Kolesnikov et al. [156]. This system was also based on $\mathrm{Nd}^{3+}$ doped crystals, but the matrix was $\mathrm{YVO}_{4}$. The thermometric performance is not very impressive, however, as the temperature resolution was $1.5 \mathrm{~K}$ and the sensitivity was $0.25 \% \mathrm{~K}^{-1}$. The system was also used to measure the subtissue temperature in chicken breast tissue under simultaneous photothermal treatment. The nanoparticles were injected at a depth of $3 \mathrm{~mm}$, and a 808 $\mathrm{nm}$ laser beam was used as a source for heating and excitation at the same time. The luminescence emission from the thermometric nanoparticles was captured with an optical fiber. Temperature differences as large as 33\% were found between the subtissue temperature and the surface temperature measured with a commercial infrared camera. 


\subsubsection{Intracellular thermometers in magnetic hyperthermia}

Thermometry in cellular hyperthermia experiments has been usually performed at bulk level in the medium with optical fibber thermometers [157]. Measurements of local temperature are very rare [158]. Within the dual-particle approach, systems have been proposed embedding UCNCs (up-conversion nanocrystals, $\mathrm{NaYF}_{4}: \mathrm{Yb}^{3+}, \mathrm{Er}^{3+}$ ) nanothermometers and MNPs (magnetic nanoparticles) in a common silica nanoparticle matrix, which mitigate in part the problems associated with this strategy [159], although the two types of particles were still 8-9 $\mathrm{nm}$ apart from each other, and the temporal resolution was too low (30 s) for a fine screening of the heat transfer process. This system has not been used in intracellular environment, however, studies in aqueous suspensions showed gradients of more than $20^{\circ} \mathrm{C}$ inside the silica nanoparticles, with respect to bulk solution temperature, that went to zero only 15-20 min after the field was switched off. Gradients were also found under low field intensity when the bulk temperature was invariant.

Concerning single-particle approach, the ideal situation would be to have a single system for heating and thermometry. As it is described later in this section, there are systems in optical hyperthermia that are close to this ideal situation [96,101], but this is not feasible in magnetic hyperthermia at the present moment because thermometers based on magnetic properties lack the spatial resolution needed for this purpose. Therefore, the thermometric sensors are incorporated to the magnetic nanoparticles in the form of molecular fluorescent probes. In an early example of single-particle approach for intracellular thermometry and heating, temperature sensing was realized through a temperature-dependent azo-bond breaking. The reporter was a fluorophore attached through a linker to the MNP shell by such a bond [160], and the detection was achieved by fluorescence analysis of the cell medium after heating. Temperature at different distances from the nanoheather can be determined using spacers with different chain length. In experiments performed in nanoparticle suspensions, temperature gradients of $45^{\circ} \mathrm{C}$, with respect to the medium bulk temperature, were estimated at 0.5 $\mathrm{nm}$ from the heather that decreased exponentially with increasing distance. This system can be improved by replacing the azo-bond by DNA double strand bonding [161] that permits to modulate the sensing temperature with the chain length, and to perform several temperature measurements along the experiment. The fluorophore in this case is attached to the end of a DNA strand while the other strand is attached to the NP coating surface at a certain distance from the heating core. DNA denaturalized at precise temperature that depends on the chain length. Therefore, this system can mark when a certain temperature is achieved at a given distance from the heat source. Temperature gradients of nearly $10^{\circ} \mathrm{C}$ were estimated at $5 \mathrm{~nm}$ from the MNP heaters (Figure 6.14). Nevertheless, the temperature reading is still discontinuous and a posteriori. These problems can be overcome with a system that combines amphiphilic copolymer coated MNPs and molecular lanthanide fluorescence thermometers. The molecular thermometers are located on the MNP surface within the hydrophobic part of the shell. This system allows a continuous temperature monitoring with high time resolution. Moreover, the thermometer is ratiometric and generates absolute temperature maps from a pixel-by-pixel conversion of fluorescence intensity images captured in the microscope camera. However, none of these systems have been used in direct cell hyperthermia studies yet. 


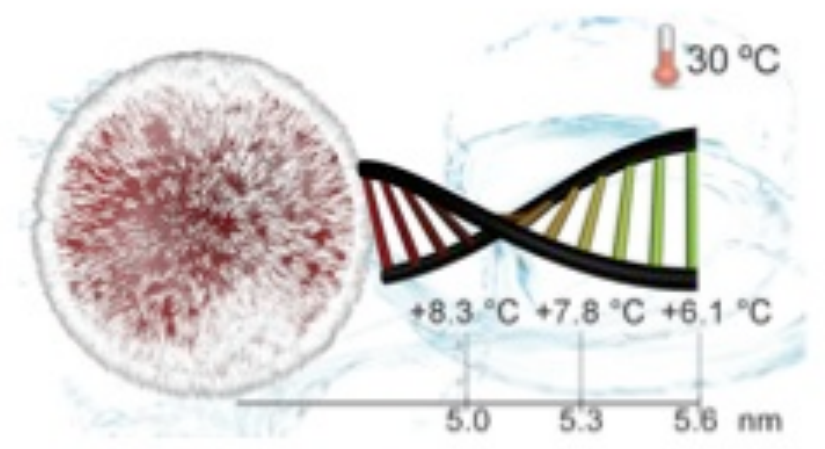

Figure 6.14. Experimentally determined temperature gradients at several distances from the heater in magnetic hyperthermia determined by DNA denaturalization thermometry. Reproduced with permission from John Wiley and Sons, ref [161].

A system that has been employed in studies of magnetic hyperthermia on HEK 293 cell membrane was based on molecular organic dye thermometry [128]. The thermometric probe was a dye, DyLight549 (orange), which was bound to the NP surface by means of a biotin-streptavidin linker. The local temperature of MNPs on the cell membrane was followed in comparison with that of Golgi apparatus collected with a GFP thermometer. A high frequency ac magnetic field was applied in this case $(40 \mathrm{MHz}, 0,67 \mathrm{kA} / \mathrm{m})$, and temperature gradients higher than $15^{\circ} \mathrm{C}$ were observed at the NP surface without any observable change in the cytoplasm (Golgi apparatus in fact) temperature. The heat generated by the NPs produced a thermal activation of membrane ion channels without observable toxic effects.

\subsection{Conclusions and perspectives.}

The ultimate aim of hyperthermia therapy would be to operate at intracellular level with a minimum amount of foreign material to achieve the desired goal of non-invasiveness, no secondary effects, and optimal performance. The application of heat can be directed to obtain direct thermal induced cell death or just as an enhancer of drug activity or as a trigger for drug release. In any case, the advance in this field requires a deep knowledge of heat generation and conduction processes within the cell, and more specifically a precise mapping of temperature gradients established within the cell during hyperthermia application. Among the different high-resolution thermometric systems available, luminescent thermometers seem to be the most adequate for this task. Although they are not fully non-contact as the infrared pyrometers, they improve the uncertainty by one order of magnitude. There are already multiple choices available among luminescent temperature probes that could be suitable for intracellular thermometry including organic dyes, ruthenium complexes, spin crossover nanoparticles, polymers, organic-inorganic hybrids, semiconductor quantum dots and $\mathrm{Ln}^{3+}$-based materials. Some of them are even operative in the biological transparent window permitting to measure the temperature inside the biological tissue. Although the development of luminescent thermometry is relatively recent, many of the systems available have successfully been applied for intracellular thermometry. Their use in nanoparticle-based hyperthermia imposes some restrictions, as they should be able to determine the temperature in the vicinities of the nanoparticle heaters. Some heaterthermometer constructions have been proposed for that purpose. In the case of optical hyperthermia, there are plenty of successful examples. Actually, the ideal case of having 
both qualities in a unique material has already been realized. In the case of magnetic hyperthermia the advances in the field are scarcer. However, it is not risky to predict that a precise screening of heat transfer processes in intracellular hyperthermia will be realized in the next few years, which will suppose a real breakthrough in the development of hyperthermia therapy.

\section{Acknowledgements}

This work was partially developed within the scope of the project CICECO-Aveiro Institute of Materials, POCI-01-0145-FEDER-007679 (FCT Ref. UID /CTM 150011/2013), financed by national funds through the FCT/MEC and when appropriate co-financed by FEDER under the PT2020 Partnership Agreement. CDSB thanks the Portuguese Fundação para a Ciência e Tecnologia (FCT) for the post-doctoral grant (SFRH/BPD/89003/2012). Financial support from the Spanish Ministry of Science and Innovation MAT2014-54975-R are gratefully acknowledged. The authors would like to acknowledge the use of Servicio General de Apoyo a la Investigación-SAI, Universidad de Zaragoza. 


\section{References}

[1] a) R.K. Gilchrist, R. Medal, W.D. Shorey, R.C. Hanselman, J.C. Parrott, C.B. Taylor, Selective inductive heating of lymph nodes, Ann. Surg. 146 (1957) 596-606; b) R.W.Y. Habash, R. Bansal, D. Krewski, H. T. Alhafid, in: M.V. Kamath (Ed.), Thermal Therapy, Part 1: An Introduction to Thermal Therapy, vol. 27, Begell: New York, 2006, pp. 459-489; c) S.H. Noha, S.H. Moona, T.H. Shina, Y. Lima, J. Cheon, Recent advances of magneto-thermal capabilities of nanoparticles: From design principles to biomedical applications, Nano Today 13 (2017) 61-76.

[2] a) B. Thiesen, A. Jordan, Clinical applications of Magnetic nanoparticles for hyperthermia, Int. J. Hyperthermia 24 (2008) 467-474; b) a) S. Dutz R. Hergt, Magnetic nanoparticle heating and heat transfer on a microscale: Basic principles, realities and physical limitations of Hyperthermia for tumour therapy, Int. J. Hyperthermia, 29(8) (2013) 790-800.

[3] a) D.E. Owens III, N. A. Peppas, Opsonization, biodistribution, and pharmacokinetics of polymeric nanoparticles, Int. J. Pharm. 307 (2006) 93-102; b) F. Alexis, E. Pridgen, L.K. Molnar, O.C. Farokhzad, Factors Affecting the Clearance and Biodistribution of Polymeric Nanoparticles, Mol. Pharm. 5 (2008) 505-515; c) E. Sadauskas, H. Wallin, W. Stoltenberg, U. Vogel, P. Doering, A. Larsen, G. Danscher, Kupffer cells are central in the removal of nanoparticles from the organism, Part. Fibre Toxicol. 4 (2007) 10.

[4] a) M. Johannsen, U. Gneveckow, B. Thiesen, K Taymoorian, H.H. Cho, N. Waldöfner, R. Scholz R, A. Jordan, S.A. Loening, P. Wust, Thermotherapy of prostate cancer using magnetic nanoparticles: Feasibility, imaging, and three-dimensional temperature distribution, Eur. Urol. 52 (2007) 1653-62; b) M. Johannsen, U. Gneveckow, K. Taymoorian, B. Thiesen, N. Waldoefner, R. Scholz, Morbidity and quality of life during thermotherapy using magnetic nanoparticles in locally recurrent prostate cancer: Results of a prospective phase I trial, Int. J. Hyperthermia 23 (2007) 315-23; c) M. Johannsen, B. Thiesen, P. Wust, A. Jordan Magnetic nanoparticle hyperthermia for prostate cancer, Int. J. Hyperthermia 26 (2010) 790-7955; d) K. MaierHauff, F. Ulrich, D. Nestler, H. Niehoff, P. Wust, B. Thiesen, H. Orawa, V. Budach, A. Jordan, Efficacy and safety of intratumoral thermotherapy using magnetic iron-oxide nanoparticles combined with external beam radiotherapy on patients with recurrent glioblastoma multiforme, J. Neurooncol.103 (2011) 317-324; e) M.H. K.Maier-Hauff, R. Rothe, R. Scholz, U. Gneveckow, P. Wust, B. Thiesen, A. Feussner, A. von Deimling, N. Waldoefner, R. Felix, A. Jordan, Intracranial thermotherapy using magnetic nanoparticles combined with external beam radiotherapy: Results of a feasibility study on patients with glioblastoma multiforme, J. Neurooncol. 81 (2007) $53-60$.

[5] C. Sanchez, D. El Hajj Diab, V. Connord, P. Clerc, E. Meunier, B. Pipy, B. Payré, R. P. Tan, M. Gougeon, J. Carrey, V. Gigoux, D. Fourmy, Targeting a G-ProteinCoupled Receptor Overexpressed in Endocrine Tumors by Magnetic Nanoparticles To Induce Cell Death, ACS Nano 8 (2) (2014) 1350-63.

[6] K.E. Goodson and M. Asheghi, Near-field optical thermometry, Microscale Thermophys. Eng. 1 (1997) 225-235.

[7] J.M. Yang, H. Yang, L. Lin, Quantum dot nano thermometers reveal heterogeneous local thermogenesis in living cells, ACS Nano 5 (6) (2011) 5067-5071.

[8] R. Tanimoto, T. Hiraiwa, Y. Nakai, Y. Shindo, K. Oka, N. Hiroi, A. Funahashi, Detection of Temperature Difference in Neuronal Cells, Sci. Rep. 6 (2016) 22071. 
[9] L.M. Maestro, E.M. Rodríguez, F. Sanz-Rodríguez, M.C. Cruz, A.J. de la Fuente, R. Naccache, F. Vetrone, D. Jaque, J.A. Capobianco, J.G. Solé, CdSe quantum dots for two-photon fluorescence thermal imaging, Nano Lett. 10 (12) (2010) 5109-5115.

[10] P. Neumann, I. Jakobi, F. Dolde, C. Burk, R. Reuter, G. Waldherr, J. Honert, T. Wolf, A. Brunner, J.H. Shim, D. Suter, H. Sumiya, J. Isoya, J. Wrachtrup, HighPrecision Nanoscale Temperature Sensing Using Single Defects in Diamond, Nano. Lett. 13 (2013) 2738-2742.

[11] C.D.S. Brites, P.P. Lima, N.J.O. Silva, A. Millán, V. Amaral, F. Palacio, and L.D. Carlos, Organic-Inorganic $\mathrm{Eu}^{3+} / \mathrm{Tb}^{3+}$ codoped hybrid films for temperature mapping in integrated circuits, Front. Chem. 1 (2013) 9.

[12] L. Aigouy, E. Saidi, L. Lalouat, J. Labeguerie-Egea, M. Mortier, P. Low, C. Bergaud, Nanoscale optical thermometry using a time-correlated single-photon counting in an illumination-collection mode, J. Appl. Phys. 106 (2009) 074301.

[13] H. Peng, M.I. Stich, J. Yu, L.N. Sun, L.H. Fischer, O.S. Wolfbeis, Luminescent Europium(III) Nanoparticles for Sensing and Imaging of Temperature in the Physiological Range. Adv. Mater., 22 (2010) 716-719.

[14] L.N. Sun, J.B. Yu, H.S. Peng, J.Z. Zhang, L.Y. Shi and O.S. Wolfbeis, Temperature-Sensitive Luminescent Nanoparticles and Films Based on a Terbium (III) Complex Probe, J. Phys. Chem. C 114 (2010) 12642-12648.

[15] S. Li, K. Zhang, J.M. Yang, L.W. Lin and H. Yang, Single Quantum Dots as Local Temperature Markers, Nano Lett. 7 (2007) 3102-3105.

[16] T.C. Liu, Z.L. Huang, H.Q. Wang, J.H. Wang, X.Q. Li, Y.D. Zhao, and Q.M. Luo, Temperature-dependent photoluminescence of water-soluble quantum dots for a bioprobe, Anal. Chim. Acta, 559 (2006) 120-123.

[17] J.H. Wang, H.Q. Wang, Y.Q. Li, H.L. Zhang, X.Q. Li, X.F. Hua, Y.C. Cao, Z.L. Huang, Y. D. Zhao, Modification of CdTe quantum dots as temperature-insensitive bioprobes, Talanta, 74 (2008) 724-729.

[18] L.M. Maestro, C. Jacinto, U.R. Silva, F. Vetrone, J.A. Capobianco, D. Jaque, J.G. Solé, Small 7 (2011) 1774-1778.

[19] V.M. Chauhan, R.H. Hopper, S.Z. Ali, E.M. King, F. Udrea, C.H. Oxley, J.W. Aylott, CdTe Quantum Dots as Nanothermometers: Towards Highly Sensitive Thermal Imaging, Sens. Actuators B: Chem. 192 (2014) 126-133.

[20] J.S. Donner, S.A. Thompson, M.P. Kreuzer, G. Baffou, R. Quidant, Mapping Intracellular Temperature Using Green Fluorescent Protein, Nano Lett. 12(4) (2012) 2107-2018.

[21] C. Gota, S. Uchiyama, T. Yoshihara, S. Tobita, T. Ohwada, TemperatureDependent Fluorescence Lifetime of a Fluorescent Polymeric Thermometer, $\operatorname{Poly}(\mathrm{N}$ isopropylacrylamide), Labeled by Polarity and Hydrogen Bonding Sensitive 4Sulfamoyl-7-aminobenzofurazan, J. Phys. Chem. B 112 (2008) 2829-2836.

[22] K. Okabe, N. Inada, C. Gota, Y. Harada, T. Funatsu and S. Uchiyama, Nat. Commun. 3 (2012) 705.

[23] S. Uchiyama, Y. Matsumura, A.P. de Silva, K. Iwai, Intracellular temperature mapping with a fluorescent polymeric thermometer and fluorescence lifetime imaging microscopy, Anal. Chem. 75 (2003) 5926-5935.

[24] O. Yarimaga, S. Lee, D.Y. Ham, J.M. Choi, S.G. Kwon, M. Im, S. Kim, J.M. Kim, Y.K. Choi, Thermofluorescent Conjugated Polymer Sensors for Nano- and Microscale Temperature Monitoring, Macromol. Chem. Phys. 212 (2011) 1211-1220.

[25] H. Kusama, O.J. Sovers, T. Yoshioka, Line Shift Method for Phosphor Temperature Measurements, Jpn. J. Appl. Phys. 15 (1976) 2349-2358. 
[26] R.B. Mikkelsen, D.F.H. Wallach, Temperature sensitivity of the erythrocyte membrane potential as determined by cyanine dye fluorescence, Cell Biol. Int. Rep. 1 (1977) 51-55.

[27] T. Samulski, P.N. Shrivastava, Photoluminescent Thermometer Probes: Temperature Measurements in Microwave Fields, Science 208 (1980) 193-194.

[28] T.V. Samulski, P.T. Chopping, B. Haas, Photo-luminescent thermometry based on europium-activated calcium sulfide, Phys. Med. Biol. 27 (1982) 107-114.

[29] C.D.S. Brites, P.P. Lima, N.J.O. Silva, Angel Millán, V.S. Amaral, F. Palacio, L.D. Carlos Thermometry at the nanoscale, Nanoscale 4 (2012) 16, 4799-4829.

[30] D. Jaque, F. Vetrone, Luminescence nanothermometry, Nanoscale 4 (2012) 43014326.

[31] X.D. Wang, O.S. Wolfbeis, R.J. Meier, Luminescent probes and sensors for temperature, Chem. Soc. Rev. 42 (2013) 7834-7869.

[32] L. Carlos, F. Palacio, Thermometry at the Nanoscale: Techniques and Selected Applications, Royal Society of Chemistry, Cambridge, 2015.

[33] C.D.S. Brites, A. Millán, L.D. Carlos, Lanthanides in Luminescent Thermometry in: J.C. Bunzli, V. Pecharsk (Eds.), Handbook on the Physics and Chemistry of Rare Earths, vol. 49, Elsevier, Amsterdam, 2016, 339-427.

[34] H. Berthou, C.K. Jörgensen, Optical-fiber temperature sensor based on upconversion-excited fluorescence, Opt. Lett. 15 (1990) 1100-1102.

[35] H.S. Peng, S.H. Huang, O.S. Wolfbeis, Ratiometric fluorescent nanoparticles for sensing temperature. J. Nanopart. Res., 2010, 12, 2729-2733.

[36] S. Uchiyama, A.P. de Silva, K. Iwai, Luminescent Molecular Thermometers, J. Chem. Educ. 83 (5) (2006) 720.

[37] C.D.S. Brites, P.P. Lima, N.J.O. Silva, A. Millán, V.S. Amaral, F. Palacio, L.D. Carlos, A Luminescent Molecular Thermometer for Long-Term Absolute Temperature Measurements at the Nanoscale, Adv. Mater. 22 (2010) 4499-4504.

[38] A.P. de Silva, H.Q.N. Gunaratne, T. Gunnlaugsson, A.J.M. Huxley, C.P. McCoy, J.T. Rademacher, T.E. Rice, Signaling Recognition Events with Fluorescent Sensors and Switches, Chem. Rev. 97 (1997) 1515-1566.

[39] J.L. Clark, P.F. Miller, G. Rumbles, Red Edge Photophysics of Ethanolic Rhodamine 101 and the Observation of Laser Cooling in the Condensed Phase, J. Phys. Chem. A 102 (1998) 4428-4437.

[40] D. Ross, M. Gaitan, L.E. Locascio, Temperature Measurement in Microfluidic Systems Using a Temperature-Dependent Fluorescent Dye, Anal. Chem. 73 (2001) 4117-4123.

[41] T. Glawdel, Z. Almutairi, S. Wang, C. Ren, Photobleaching absorbed Rhodamine B to improve temperature measurements in PDMS microchannels, Lab Chip 9 (2009) 171-174.

[42] X.L. Guan, X.Y. Liu, Z.X. Su, Preparation and photophysical behaviors of fluorescent chitosan bearing fluorescein: Potential biomaterial as temperature $/ \mathrm{pH}$ probes, J. Appl. Polym. Sci. 104 (2007) 3960-3966.

[43] P. Haro-Gonzalez, W.T. Ramsay, L. Martinez Maestro, B. del Rosal, K. SantacruzGomez, M.C. Iglesias de la Cruz, F. Sanz-Rodríguez, J.Y. Chooi, P. Rodríguez Sevilla, M. Bettinelli, D. Choudhury, A.K. Kar, J.G. Solé, D. Jaque, L. Paterson, Quantum DotBased Thermal Spectroscopy and Imaging of Optically Trapped Microspheres and Single Cells, Small 9 (2013) 2162-2170.

[44] S.J. Cho, D. Maysinger, M. Jain, B. Roder, S. Hackbarth, F.M. Winnik, LongTerm Exposure to CdTe Quantum Dots Causes Functional Impairments in Live Cells, Langmuir 23 (2007) 1974-1980. 
[45] A. Gnach, T. Lipinski, A. Bednarkiewicz, J. Rybka, J.A. Capobianco, Upconverting nanoparticles: assessing the toxicity, Chem. Soc. Rev. 44 (2015) 15611584.

[46] J.C. Bunzli, Benefiting from the Unique Properties of Lanthanide Ions, Acc. Chem. Rese. 39 (2006) 53-61.

[47] L.D. Carlos, R.A.S. Ferreira, V. de Zea Bermudez, S.J.L. Ribeiro, LanthanideContaining Light-Emitting Organic-Inorganic Hybrids: A Bet on the Future, Adv. Mater. 21 (2009) 509-534.

[48] S. Comby, J.-C. G. Bünzli, in: K. A. Gschneidner Jr., J.C.G. Bünzli, V.K. Pecharsky (Eds.), Handbook on the Physics and Chemistry of Rare Earths, Elsevier Science, B. V., New York, vol. 37, 2007 (Chapter 235) , pp. 217-470.

[49] J.C.G. Bünzli, Lanthanide Luminescence for Biomedical Analyses and Imaging, Chem. Rev. 110 (2010) 2729-2755.

[50] J.C.G. Bünzli, S. V. Eliseeva, Intriguing aspects of lanthanide luminescence, Chem. Sci. 4 (2013) 1939-1949.

[51] J.C.G. Bünzli, On the design of highly luminescent lanthanide complexes, Coord. Chem. Rev. 293 (2015) 19-47.

[52] K. Binnemans, Lanthanide-Based Luminescent Hybrid Materials. Chem. Rev. 109 (2009) 4283-4374.

[53] J. Feng, H.J. Zhang, Hybrid materials based on lanthanide organic complexes: a review, Chem. Soc. Rev. 42 (2013) 387-410.

[54] G.Y. Chen, C.H. Yang, P.N. Prasad, Nanophotonics and Nanochemistry: Controlling the Excitation Dynamics for Frequency Up- and Down-Conversion in Lanthanide-Doped Nanoparticles, Accounts Chem. Res. 46 (2013) 1474-1486.

[55] X.D. Wang, R.J. Meier, O.S. Wolfbeis, Fluorescent pH-Sensitive Nanoparticles in an Agarose Matrix for Imaging of Bacterial Growth and Metabolism, Angew. Chem.Int. Ed. 52 (2013) 406-409.

[56] Parker D. Luminescent lanthanide sensors for $\mathrm{pH}, \mathrm{O}_{2}$ and selected anions, Coord. Chem. Rev. 205 (2000) 109-130.

[57] Z.P. Wang, D. Ananias, A. Carne-Sanchez, C.D.S. Brites, I. Imaz, D. Maspoch, J. Rocha, L.D. Carlos, Lanthanide-Organic Framework Nanothermometers Prepared by Spray-Drying, Adv. Funct. Mater. 25 (2015) 2824-2830.

[58] Y. Cui, F. Zhu, B. Chen, G. Qian, Metal-organic frameworks for luminescence thermometry. Chem. Commun. 51 (2015) 7420-7431.

[59] A. Cadiau, C.D. S. Brites, P. M. F. J. Costa, R. A. S. Ferreira, J. Rocha, L. D. Carlos, Ratiometric Nanothermometer Based on an Emissive $\mathrm{Ln}^{3+}$-Organic Framework, ACS Nano 7 (2013) 7213-7218.

[60] F. Vetrone, R. Naccache, A. Zamarrón, A. Juarranz, F. Sanz-Rodríguez, L.M. Maestro, E.M. Rodriguez, D. Jaque, J.G. Solé, J.A. Capobianco, Temperature Sensing Using Fluorescent Nanothermometers. ACS Nano 4 (6) (2010) 3254-3258.

[61] O.A. Savchuk, P. Haro-González, J.J. Carvajal, D. Jaque, J. Massons, M. Aguiló, F. Diaz, Er: $\mathrm{Yb}: \mathrm{NaY}_{2} \mathrm{~F}_{5} \mathrm{O}$ up-converting nanoparticles for sub-tissue fluorescence lifetime thermal sensing, Nanoscale 6 (2014) 9727-9733.

[62] V. Lojpur, M.G. Nikolić, M.D. Dramićanin, Luminescence thermometry below room temperature via up-conversion emission of $\mathrm{Y}_{2} \mathrm{O}_{3}: \mathrm{Yb}^{3+}, \mathrm{Er}^{3+}$ nanophosphors, $\mathrm{J}$. Appl. Phys. 115 (2014) 203106.

[63] U. Rocha, K.U. Kumar, C. Jacinto, I. Villa, F. Sanz-Rodríguez, M.C. Iglesias de la Cruz, A. Juarranz, E. Carrasco, F.C. van Veggel, E. Bovero, J.G. Solé, D. Jaque, Neodymium-Doped $\mathrm{LaF}_{3}$ Nanoparticles for Fluorescence Bioimaging in the Second Biological Window, Small 10 (2014) 1141-1154. 
[64] A. Benayas, B. del Rosal, A. Perez-Delgado, K. Santacruz-Gomez, D. Jaque, G.A. Hirata, F. Vetrone, Nd:YAG Near-Infrared Luminescent Nanothermometers, Adv. Opt. Mater. 3 (2015) 687-694.

[65] S. Balabhadra, M.L. Debasu, C.D. Brites, L.A. Nunes, O.L. Malta, J. Rocha, M. Bettinelli, L.D. Carlos, Boosting the sensitivity of $\mathrm{Nd}^{3+}$-based luminescent nanothermometers, Nanoscale 7 (2015) 17261-17267.

[66] S.P. Wang, S. Westcott, W. Chen, Nanoparticle Luminescence Thermometry. J. Phys. Chem. B 106 (2002) 11203-11209.

[67] M.A.R.C. Alencar, G.S. Maciel, C.B. de Araújo, A. Patra, $\mathrm{Er}^{3+}$-doped $\mathrm{BaTiO}_{3}$ nanocrystals for thermometry: influence of nanoenvironment on the sensitivity of a fluorescence based temperature sensor, Appl. Phys. Lett. 84 (23) (2004) 4753-4755.

[68] M.D. Shinn, W.A. Sibley, M.G. Drexhage, R.N. Brown, Optical transitions of Er ${ }^{3+}$ ions in fluorozirconate glass, Phys. Rev. B 27 (1983) 6635-6648.

[69] S. Collins, G. Baxter, S. Wade, T. Sun, K. Grattan, Z. Zhang, A. Palmer, Comparison of fluorescence-based temperature sensor schemes: theoretical analysis and experimental validation, J. Appl. Phys. 84 (1998) 4649-4654.

[70] C.D.S. Brites, P.P. Lima, N.J.O. Silva, A. Millán, V.S. Amaral, F. Palacio, L.D. Carlos, Ratiometric highly sensitive luminescent nanothermometers working in the room temperature range, Applications to heat propagation in nanofluids, Nanoscale 5 (2013) 7572-7580.

[71] C.D.S. Brites, P.P. Lima, L.D. Carlos, Tuning the sensitivity of $\mathrm{Ln}^{3+}$-based luminescent molecular thermometers through ligand design, J. Lumin. 169 B (2016) 497-502.

[72] K. Miyata, Y. Konno, T. Nakanishi, A. Kobayashi, M. Kato, K. Fushimi, Y. Hasegawa, Chameleon Luminophore for Sensing Temperatures: Control of Metal-toMetal and Energy Back Transfer in Lanthanide Coordination Polymers, Angew. Chem.Int. Edit. 52 (2013) 6413-6416.

[73] C.V. Rodrigues, L.L. Luz, J.D. Dutra, S.A. Junior, O.L. Malta, C.C. Gatto, H.C. Streit, R.O. Freire, C. Wickleder, M.O. Rodrigues, Unusual photoluminescence properties of the 3D mixed-lanthanide-organic frameworks induced by dimeric structures: a theoretical and experimental approach, Phys. Chem. Chem. Phys. 16 (2014) 14858-14866.

[74] S. Sato, R. Yamaguchi, T. Nose, Temperature sensors by multicolor- fluorescent films of rare earth chelate compounds, IEIEC J. J72-C2 (1989) 906-911 (in Japanese).

[75] Y. Liu, G.D. Qian, Z.Y. Wang, M.Q. Wang, Temperature-dependent luminescent properties of Eu-Tb complexes synthesized in situ in gel glass, Appl. Phys. Lett. 86 (2005) 071907.

[76] T.J. Quinn, Temperature, Academic Press, London, 1990.

[77] B. Fellmuth, J. Fischer, G. Machin, S. Picard, P.P.M. Steur, O. Tamura, D.R. White, H. Yoon, The kelvin redefinition and its mise en pratique, Phil. Trans. R. Soc. A. 374 (2016) 20150037.

[78] S. Balabhadra, M.L. Debasu, C.D.S. Brites, R.A. Ferreira, L.D. Carlos, Upconverting Nanoparticles Working As Primary Thermometers In Different Media, J. Phys. Chem. C 121 (2017) 13962-13968.

[79] S.A. Wade, S.F. Collins, G.W. Baxter, Fluorescence intensity ratio technique for optical fiber point temperature sensing, J. Appl. Phys. 94 (2003) 4743.

[80] E.J. McLaurin, L.R. Bradshaw, D.R. Gamelin, Dual-Emitting Nanoscale Temperature Sensors, Chem. Mater. 25 (2013) 1283-1292. 
[81] Y. Zhou, B. Yan, F. Lei, Postsynthetic lanthanide functionalization of nanosized metal-organic frameworks for highly sensitive ratiometric luminescent thermometry, Chem. Commun. 50 (2014) 15235-15238.

[82] E. Carrasco, B. del Rosal, F. Sanz-Rodríguez, A.J. de la Fuente, P.H. Gonzalez, U. Rocha, K.U. Kumar, C. Jacinto, J.G. Solé, D. Jaque, Intratumoral Thermal Reading During Photo-Thermal Therapy by Multifunctional Fluorescent Nanoparticles, Adv. Funct. Mater. 25 (2015) 615-626.

[83] E.N. Cerón, D.H. Ortgies, B. Del Rosal, F. Ren, A. Benayas, F. Vetrone, D. Ma, F. Sanz-Rodríguez, J. García Solé, D. Jaque, E.M. Rodríguez, Hybrid Nanostructures for High-Sensitivity Luminescence Nanothermometry in the Second Biological Window, Adv. Mater. 27 (32) (2015) 4781-4787.

[84] P.V. dos Santos, M.T. de Araujo, A.S. Gouveia-Neto, J.A. Medeiros Neto, A.S.B. Sombra, Optical temperature sensing using upconversion fluorescence emission in $\mathrm{Er}^{3+} / \mathrm{Yb}^{3+}$-codoped chalcogenide glass, Appl. Phys. Lett. 73 (1998) 578-580.

[85] K. Kim, W.H. Jeong, W.C. Lee, P. Reddy, Ultra-High Vacuum Scanning Thermal Microscopy for Nanometer Resolution Quantitative Thermometry, ACS Nano 6 (2012) 4248-4257.

[86] T. Miyagawa, T. Fujie, Ferdinandus, T.T.V. Doan, H. Sato, S. Takeoka, Glue-Free Stacked Luminescent Nanosheets Enable High-Resolution Ratiometric Temperature Mapping in Living Small Animals, ACS Appl. Mater. Interfaces 8 (2016) 33377-33385. [87] Ferdinandus, S. Arai, S. Takeoka, S. Ishiwata, M. Suzuki, H. Sato, Facilely Fabricated Luminescent Nanoparticle Thermosensor for Real-Time Microthermography in Living Animals, ACS Sensors 1 (2016) 1222-1227.

[88] E.C. Ximendes, U. Rocha, T.O. Sales, N. Fernández, F. Sanz-Rodríguez, I.R. Martín, C. Jacinto, D. Jaque, In Vivo Subcutaneous Thermal Video Recording by Supersensitive Infrared Nanothermometers, Adv. Funct. Mater. 27 (38) (2017) 1702249.

[89] E.C. Ximendes, U. Rocha, B. del Rosal, A. Vaquero, F.S. Rodríguez, L. Monge, F. Ren, F. Vetrone, D. Ma, J.G. Solé, In Vivo Ischemia Detection by Luminescent Nanothermometers, Adv. Healthcare Mater. 6 (2017) 1601195.

[90] R. Piñol, C.D.S. Brites, R. Bustamante, A. Martínez, N.J.O. Silva, J.L. Murillo, R. Cases, J. Carrey, C. Estepa, C. Sosa, F. Palacio, L.D. Carlos, A. Millán, Joining TimeResolved Thermometry and Magnetic-Induced Heating in a Single Nanoparticle Unveils Intriguing Thermal Properties, ACS Nano 9 (3) (2015) 3134-3142.

[91] E.C. Ximendes, W.Q. Santos, U. Rocha, U.K. Kagola, F. Sanz-Rodríguez, N. Fernández, A.D.S. Gouveia-Neto, D. Bravo, A.M. Domingo, B. del Rosal, Unveiling in vivo subcutaneous thermal dynamics by infrared luminescent nanothermometers, Nano Lett. 16 (3) (2016) 1695-1703 (2016).

[92] C.D.S. Brites, X. Xie, M. L. Debasu, X. Qin, R. Chen, W. Huang, J. Rocha, X. Liu, L.D. Carlos, Instantaneous ballistic velocity of suspended Brownian nanocrystals measured by upconversion nanothermometry, Nat. Nanotech. 11 (2016) 851-856.

[93] C.D.S. Brites, M.C. Fuertes, P.C. Angelomé, E.D. Martínez, P.P. Lima, G.J.A.A. Soler-Illia, L.D. Carlos, Tethering Luminescent Thermometry and Plasmonics: Light Manipulation to Assess Real-Time Thermal Flow in Nanoarchitectures, Nano Lett. 17 (8) (2017) 4746-4752.

[94] J. Verma, S. Lal, C.J.F. Van Noorden, Nanoparticles for hyperthermic therapy: synthesis strategies and applications in glioblastoma, Int. J. Nanomed. 9 (2014) 28632877. 
[95] D. de Melo-Diogo, C. Pais-Silva, D. R. Dias, A. F. Moreira, I. J. Correia, Strategies to Improve Cancer Photothermal Therapy Mediated by Nanomaterials, Adv. Healthcare Mater. 6 (2017) 1700073.

[96]. U. Rocha, K.U. Kumar, C. Jacinto, J. Ramiro, A.J. Caamano, J.G. Solé, D. Jaque, $\mathrm{Nd}^{3+}$ doped LaF3 nanoparticles as self-monitored photo-thermal agents, Appl. Phys. Lett. 104 (2014) 053703.

[97] D. Jaque, L.M. Maestro, B. Del Rosal, P. Haro-Gonzalez, A. Benayas, J. Plaza, E. M. Rodríguez, J.G. Solé, Nanoparticles for photothermal therapies, Nanoscale 6 (2014) 9494-9530.

[98] A.K. Silva, A. Nicolas-Boluda, L. Fouassier, F. Gazeau, Overcoming the tumor microenvironment: the role of nanohyperthermia, Nanomedicine 12 (2017) 1213-1215.

[99] N. Lee, D. Yoo, D. Ling, M.H. Cho, T. Hyeon, J. Cheon, Iron Oxide Based Nanoparticles for Multimodal Imaging and Magnetoresponsive Therapy, Chem. Rev. 115 (2015) 10637-10689.

[100] D. Wawrzynczyk, A. Bednarkiewicz, M. Nyk, W. Strek, M. Samoc, Neodymium(III) doped fluoride nanoparticles as non-contact optical temperature sensors, Nanoscale 4 (2012) 6959-6961.

[101] M.L. Debasu, D. Ananias, I. Pastoriza-Santos, L.M. Liz-Marzan, J. Rocha, L.D. Carlos, All-In-One Optical Heater-Thermometer Nanoplatform Operative From 300 to $2000 \mathrm{~K}$ Based on $\mathrm{Er}^{3+}$ Emission and Blackbody Radiation, Adv. Mater. 25 (35) (2013) 4868-4874.

[102] U. Rocha, C. Jacinto da Silva, W. Ferreira Silva, I. Guedes, A. Benayas, L.M. Maestro, M. Acosta Elias, E. Bovero, F.C.J.M. van Veggel, J.G. Solé, D. Jaque, Subtissue Thermal Sensing Based on Neodymium-Doped $\mathrm{LaF}_{3}$ Nanoparticles, ACS Nano 7 (2) (2013) 1188-1199.

[103] G. Jalani, R. Naccache, D.H. Rosenzweig, L. Haglund, F. Vetrone, M. Cerruti, Photocleavable Hydrogel-Coated Upconverting Nanoparticles: A Multifunctional Theranostic Platform for NIR Imaging and On-Demand Macromolecular Delivery, J. Am. Chem. Soc. 138 (2016) 1078-1083.

[104] D.K. Roper, W. Ahn, M. Hoepfner, Microscale Heat Transfer Transduced by Surface Plasmon Resonant Gold Nanoparticles, J. Phys. Chem. C 111 (2007) 36363641.

[105] O.A. Savchuk, J.J. Carvajal, J. Massons, M. Aguiló, F. Diaz, Determination of photothermal conversion efficiency of graphene and graphene oxide through an integrating sphere method, Carbon 103 (2016) 134-141

[106] B. del Rosal, U. Rocha, E.C. Ximendes, E.M. Rodriguez, D. Jaque, J.G. Solé, $\mathrm{Nd}^{3+}$ ions in nanomedicine: Perspectives and applications, Opt. Mater. 63 (2017) 185196.

[107] B. del Rosal, A. Perez-Delgado, E. Carrasco, D.J. Jovanovic, M.D. Dramicanin, G. Drazic, A. J. de la Fuente, F. Sanz-Rodriguez, D. Jaque, Neodymium-Based Stoichiometric Ultrasmall Nanoparticles for Multifunctional Deep-Tissue Photothermal Therapy, Adv. Opt. Mater. 4 (5) (2016) 782-789.

[108] L. Marciniak, A. Pilch, S. Arabasz, D. Jin, A. Bednarkiewicz, Heterogeneously $\mathrm{Nd}^{3+}$ doped single nanoparticles for NIR-induced heat conversion, luminescence, and thermometry, Nanoscale 9 (2017) 8288-8297.

[109] O. Savchuk, J. Carvajal, C.D.S. Brites, L.D. Carlos, M. Aguilo, F. Diaz. Upconversion thermometry: a new tool to measure the thermal resistance of nanoparticles, Nanoscale 2018, 10.1039/C7NR08758F.

[110] R. Prasher, Predicting the Thermal Resistance of Nanosized Constrictions, Nano Letters 5 (2005) 2155-2159. 
[111] T. Bai, N. Gu, Micro/Nanoscale Thermometry for Cellular Thermal Sensing, Small 12 (34) (2016) 4590-4610.

[112] K. Rosenthal, V. Oehling, C. Dusny, A. Schmid, Beyond the bulk: disclosing the life of single microbial cells, FEMS Microbiol. Rev. 41(6) (2017) 751-780.

[113] B. del Rosal, E.M. Rodríguez, L.M. Maestro, P. Haro-González, J.G. Solé, Fluorescent nanothermometers for intracellular thermal sensing, Nanomedicine (Lond) 9 (7) (2014) 1047-1062.

[114] Chapman C.F., Y. Liu, G.J. Sonek, B.J. Tromberg, "The use of exogenous fluorescent-probes for temperature-measurements in single living cells," Photochem. Photobiol. 62 (3) (1995) 416-425.

[115] J. Coppeta, C. Rogers, Dual emission laser induced fluorescence for direct planar scalar behavior measurements, Experiments in Fluids 25 (1) (1998) 1-15.

[116] C. Paviolo, A.H.A. Clayton, S.L. McCarthur, P.R. Stoddart, Temperature measurement in the microscopic regime: a comparison between fluorescence lifetimeand intensity-based methods, J. Microsc. 250 (3) (2013) 179-188.

[117] S. Arai, M. Suzuki, S.J. Park, J.S. Yoo, L. Wang, N.Y. Kang, H.H. Haf, Y.T. Chang, Mitochondria-targeted fluorescent thermometer monitors intracellular temperature gradient, Chem. Commun. 51 (38) (2015) 8044-8051.

[118] H. Huang, S. Delikanli, H. Zeng, D.M. Ferkey, A. Pralle, Remote control of ion channels and neurons through magnetic-field heating of nanoparticles, Nature Nanotechnol. 5 (8) (2010) 602-606.

[119] M. Homma, Y. Takei, A. Murata, T. Inouea, S. Takeoka, A ratiometric fluorescent molecular probe for visualization of mitochondrial temperature in living cells, Chem. Comm. 51 (28) (2015) 6194-6197.

[120] O. Zohar, M. Ikeda, H. Shinagawa, H. Inoue, H. Nakamura, D. Elbaum, D.L. Alkon, T. Yoshioka Thermal imaging of receptor-activated heat production in single cells, Biophysical Journal. 74 (1998) 82-89.

[121] J. Qiao, X. Mu, L. Qi, Construction of fluorescent polymeric nano-thermometers for intracellular temperature imaging: A review, Biosensors and Bioelectronics 85 (2016) 403-413.

[122] Y. Takei, S. Arai, A. Murata, M. Takabayashi, K. Oyama, S. Ishiwata, S. Takeoka, M. Suzuki, A Nanoparticle-Based Ratiometric and Self-Calibrated Fluorescent Thermometer for Single Living Cells, ACS Nano 8 (1) (2014) 198-206.

[123] C. Gota, K. Okabe, T. Funatsu, Y. Harada, S. Uchiyama, Hydrophilic fluorescent nanogel thermometer for intracellular thermometry, J. Am. Chem. Soc. 131(8) (2009) 2766-2773.

[124] T. Hayashi, N. Fukuda, S. Uchiyama, N. Inada, A cell-permeable fluorescent polymeric thermometer for intracellular temperature mapping in mammalian cell lines, PLoS One 10 (2) (2015) e0117677.

[125] S. Uchiyama, T. Tsuji, K. Ikado, A. Yoshida, K. Kawamoto, T. Hayashi T,N. Inada, A cationic fluorescent polymeric thermometer for the ratiometric sensing of intracellular temperature, Analyst. 140 (13) (2015) 4498-4506.

[126] X. Hu, Y. Li, T. Liu, G. Zhang, S. Liu, Intracellular cascade FRET for temperature imaging of living cells with polymeric ratiometric fluorescent thermometers, ACS Appl. Mater. Interfaces 7(28) (2015) 15551-60.

[127] Y. Wu, J. Liu, Y. Wang, K. Li, L. Li, J. Xu, D. Wu, Novel Ratiometric Fluorescent Nanothermometers Based on Fluorophores-Labeled Short Single-Stranded DNA, ACS Appl. Mater. Interfaces 9 (12) (2017) 11073-11081.

[128] G. Kucsko, P.C. Maurer, N.Y. Yao, M. Kubo, H.J. Noh, P.K. Lo, H. Park, M.D. Lukin, Nanometre-scale thermometry in a living cell. Nature. 500 (7460) (2013) 54-62. 
[129] C. Wang, H. Lin, Z. Xu, Y. Huang, M.G. Humphrey, C. Zhang, Tunable CarbonDot-Based Dual-Emission Fluorescent Nanohybrids for Ratiometric Optical Thermometry in Living Cells, ACS Appl. Mater. Interfaces 8 (10) (2016) 6621-6628.

[130] S. Kalytchuk, K. Poláková, Y. Wang, J. P. Froning, K. Cepe, A.L. Rogach, R. Zbořil, Carbon Dot Nanothermometry: Intracellular Photoluminescence Lifetime Thermal Sensing, ACS Nano 11 (2) (2017) 1432-1442.

[131] Y. Yang, W. Kong, H. Li, J. Liu, M. Yang, H. Huang, Y. Liu, Z. Wang, Z. Wang, T.K. Sham, J. Zhong, C. Wang, Z. Liu, S.T. Lee, Z. Kang, Fluorescent N-Doped Carbon Dots as in Vitro and in Vivo Nanothermometer, ACS Appl. Mater. Interfaces 7 (49) (2015) 27324-27330.

[132] L. Wei, Y. Ma, X. Shi, Y. Wang, X. Su, C. Yu, S. Xiang, L. Xiao, B. Chen, Living cell intracellular temperature imaging with biocompatible dye-conjugated carbon dot, J. Mater. Chem. B 5 (18) (2017) 3383-3390.

[133] L. Shang, F. Stockmar, N. Azadfar, G.U. Nienhaus, Intracellular Thermometry by Using Fluorescent Gold Nanoclusters, Angew. Chem. Int. Ed. 52 (42) (2013) 1115411157.

[134] A. Millán, L.D. Carlos, C.D.S. Brites, N.J.O. Silva, R. Piñol, F. Palacio, OrganicInorganic Hybrids Thermometry in: L.D. Carlos, F. Palacio (Ed.), RSC Nanoscience \& Nanotechnology, No. 38, Thermometry at the Nanoscale: Techniques and Selected Applications, The Royal Society of Chemistry, Cambridge, 2016, pp. 237-372.

[135] H. Liu, Y. Fan, J. Wang, Z. Song, H. Shi, R. Han, Y. Sha, Y. Jiang, Intracellular Temperature Sensing: An Ultra-bright Luminescent Nanothermometer with Nonsensitivity to $\mathrm{pH}$ and Ionic Strength, Sci. Rep. 5 (2015) 14879.

[136] D. Jaque, L.M. Maestro, E. Escudero, E.M. Rodríguez, J.A. Capobianco, F. Vetrone, A. Juarranz de la Fuente, F. Sanz-Rodríguez, M.C. Iglesias-delaCruz, C. Jacinto, U. Rocha, J.G. Solé, Fluorescent nano-particles for multi-photon thermal sensing, J. Luminescence 133 (2013) 249-253.

[137] J. Qiao, Y.H. Hwang, C.F. Chen, Li Qi, P. Dong, X.Y. Mu, D.P. Kim, Ratiometric Fluorescent Polymeric Thermometer for Thermogenesis Investigation in Living Cells, Anal. Chem., 2015, 87 (20), pp. 10535-10541.

[138] Y. Kamei, M. Suzuki, K. Watanabe, K. Fujimori, T. Kawasaki, T. Deguchi, Y. Yoneda, T. Todo, S. Takagi, T. Funatsu, S. Yuba, Infrared laser-mediated gene induction in targeted single cells in vivo, Nat. Methods. 6 (1) (2009) 79-81.

[139] S. Kiyonaka, T. Kajimoto, R. Sakaguchi, D. Shinmi, M. Omatsu-Kanbe, H. Matsuura, H. Imamura, T. Yoshizaki, I. Hamachi, T. Morii, Y. Mori, Genetically encoded fluorescent thermosensors visualize subcellular thermoregulation in living cells, Nat. Methods. 10(12) (2013) 1232-1240.

[140] M Nakano, Y. Arai, I. Kotera, K. Okabe, Y. Kamei, T. Nagai, Genetically encoded ratiometric fluorescent thermometer with wide range and rapid response, PLoS ONE 12(2) (2017) e0172344 (1-14).

[141] K.M. McCabe, E.J. Lacherndo, I. Albino-Flores, E. Sheehan, M. Hernandez, MacCabe, LacI(Ts)-Regulated Expression as an In Situ Intracellular Biomolecular Thermometer, Appl. Environ. Microbiol. 77 (9) (2011) 2863-2868.

[142] F. Yang, G. Li, J. Yang, Z. Wang, D. Han, F. Zheng, S. Xu, Measurement of local temperature increments induced by cultured HepG2 cells with microthermocouples in a thermally stabilized System, Sci. Rep. 7 (2017) 1721 (1-11).

[143] M. Suzuki, V. Tseeb, K. Oyama, S. Ishiwata, Microscopic Detection of Thermogenesis in a Single HeLa Cell, Biophys. J. 92(6) (2007) L46-L48.

[144] L.M. Maestro, P. Haro-González, M. Iglesias-de la Cruz, F. Sanz-Rodríguez, A. Juarranz, J.G. Solé, D. Jaque, Fluorescent Nanothermometers Provide Controlled 
Plasmonic- Mediated Intracellular Hyperthermia, Nanomedicine (London, U. K.) 8 (3) (2013) 379-388.

[145] J.S. Donner, S. A. Thompson, M. P. Kreuzer, G. Baffou, R. Quidant, Mapping Intracellular Temperature Using Green Fluorescent Protein, Nano Lett. 12 (4) (2012) 2107-2111.

[146] J.S. Donner, S.A. Thompson, C. Alonso-Ortega, J. Morales, L.G. Rico, S.I.C. O Santos, R Quidant, Imaging of Plasmonic Heating in a Living Organism, ACS Nano 7 (10) (2013) 8666-8672.

[147] A. Marino, S. Arai, Y. Hou, A. Degl'Innocenti, V. Cappello, B. Mazzolai, Y. Chang, V. Mattoli, M. Suzuki, G. Ciofani, Gold Nanoshell-Mediated Remote Myotube Activation, ACS Nano 11 (3) (2017) 2494-2508.

[148] L. Yang, H.S. Peng, H. Ding, F.T. You, L.L. Hou, F. Teng, Luminescent $\mathrm{Ru}(\mathrm{bpy})_{3}{ }^{2+}$-doped silica nanoparticles for imaging of intracellular temperature, Microchim. Acta 181 (7-8) (2014) 743-749.

[149] P. Rodríguez-Sevilla, Y. Zhang, P. Haro-González, F. Sanz-Rodríguez, F. Jaque, J.G. Solé, X. Liu, D. Jaque, Thermal Scanning at the Cellular Level by an Optically Trapped Upconverting Fluorescent Particle, Adv. Mater. 28 (12) (2016) 2421-2426.

[150] L.M. Maestro, P. Haro-González, B. del Rosal, J. Ramiro, A. J. Caamaño, E. Carrasco, A. Juarranz, F. Sanz-Rodríguez, J.G. Solé, D. Jaque, Heating efficiency of multi-walled carbon nanotubes in the first and second biological windows, Nanoscale 5 (2013) 7882-7889.

[151] S. Freddi, L. Sironi, R. D'Antuono, D. Morone, A. Dona, E. Cabrini, L. D'Alfonso, M. Collini, P. Pallavicini, G. Baldi, D. Maggioni, G. Chirico, A Molecular Thermometer for Nanoparticles for Optical Hyperthermia, Nano Lett. 13 (5) (2013) 2004-2010.

[152] K. Nigoghossian, S. Ouellet, J. Plain, Y. Messaddeq, D. Boudreau, S.J.L. Ribeiro, Upconversion nanoparticle-decorated gold nanoshells for near-infrared induced heating and thermometry, J. Mater. Chem. B 5 (34) (2017) 7109-7117.

[153] M.L. Debasu, C.D.S. Brites, S. Balabhadra, H. Oliveira, J. Rocha, L.D. Carlos, Nanoplatforms for Plasmon-Induced Heating and Thermometry, ChemNanoMat, 2 (2016) 520-527.

[154] U. Rocha, J. Hu, E.M. Rodríguez, A.S. Vanetsev, M. Rähn, V. Sammelselg, Y.V. Orlovskii, J.G. Solé, D. Jaque, D.H. Ortgies, Subtissue Imaging and Thermal Monitoring of Gold Nanorods through Joined Encapsulation with Nd-Doped InfraredEmitting Nanoparticles, Small 12 (2016) 5394-5400.

[155] B. del Rosal, E. Carrasco, F. Ren, A. Benayas, F. Vetrone, F. Sanz-Rodríguez, D. Ma, A. Juarranz, D. Jaque, Infrared-Emitting QDs for Thermal Therapy with Real-Time Subcutaneous Temperature Feedback, Adv. Funct. Mater. 2633 (2016) 6060-6068.

[156] I.E. Kolesnikov, E.V. Golyeva, A.A. Kalinichev, M.A. Kurochkin, E. Lähderanta, M.D. Mikhailov, $\mathrm{Nd}^{3+}$ single doped YVO4 nanoparticles for sub-tissue heating and thermal sensing in the second biological window, Sens. Actuators B Chem. 243 (2017) 338-345.

[157] R. Di Corato, A. Espinosa, L. Lartigue, M. Tharaud, S. Chat, T. Pellegrino, C. Ménager, F. Gazeau, C. Wilhelm, Magnetic hyperthermia efficiency in the cellular environment for different nanoparticle designs, Biomaterials 35 (24) (2014) 6400-6411 [158] A. Chiu-Lam, C. Rinaldi, Nanoscale Thermal Phenomena in the Vicinity of Magnetic Nanoparticles in Alternating Magnetic Fields, Adv. Funct. Mater. 26 (22) (2016) 3933-3941.

[159] J. Dong, J. I. Zink, Taking the Temperature of the Interiors of Magnetically Heated Nanoparticles. ACS Nano 8 (2014) 5199-5207. 
[160] A. Riedinger, P. Guardia, A. Curcio, M.A. Garcia, R. Cingolani, L. Manna, T. Pellegrino, Subnanometer Local Temperature Probing and Remotely Controlled Drug Release Based on Azo-Functionalized Iron Oxide Nanoparticles, Nano Lett.

13 (6) (2013) 2399-2406.

[161] J.T. Dias, M. Moros, P. del Pino, S. Rivera, V. Grazu, J.M. de la Fuente, DNA as a Molecular Local Thermal Probe for the Analysis of Magnetic Hyperthermia, Angew. Chem., Int. Ed. 52 (44) (2013) 11526-11529. 